\title{
Effect of Pintool Rotational Speed on Friction Stir Welding (FSW) Thermal Energy Generation using Different Friction Models
}

\author{
Saad Aziz, Muhammad Wahab* \\ Department of Mechanical \& Industrial Engineering, \\ Louisiana State University, LA 70803, USA
}

\begin{abstract}
In this present work four different models have been used to simulate and analyze the interaction process of Friction- Stir Welding (FSW). These models are: (i) Coulomb model with constant friction coefficient, (ii) modified Coulomb model with constant friction coefficient, (iii) modified Coulomb model with temperature dependent friction coefficient, and (iv) modified Coulomb friction model with temperature dependent friction coefficient and temperature dependent material properties for workpiece. Results obtained from different models show that the modified Coulomb friction model with temperature dependent friction coefficient along with temperature dependent material properties of the workpiece results in the closest temperature profiles compared to experimental temperature history. Three different pintool rotational speed e.g., low, moderate, and high rotation speed has been used for comparison among the four different models mentioned above. At low and high rotational speeds, Coulomb model (C-model) generates higher friction energy compare to modified Coulomb model. At moderate rotational speed, no such difference is observed among the Coulomb and modified Coulomb model. In modified Coulomb model, friction stress is limited to $\frac{\sigma_{y}}{\sqrt{3}}$ instead of the multiplication of the friction coefficient and the solution-dependent contact pressure calculated in the Coulomb friction model. For all given rotational speeds, Coulomb model exhibits high plastic dissipation energy compare to the models developed using the modified Coulomb model. At low rotational speeds, Coulomb model shows extremely high plastic energy and maximum equivalent plastic strain compare to other models, which is not corroborated experimentally. Therefore, it is concluded that the Coulomb model is not capable of accurately capturing contact phenomena between pintool/workpiece accurately at low pintool rotational speed.
\end{abstract}

Keyword: Coulomb model, modified Coulomb model, friction -stir -welding (FSW); contact modeling; frictional dissipation energy, temperature distribution, aluminum alloy, plastic dissipation energy, rotational speed.

\section{I.INTRODUCTION}

Welding is considered one of the most important inventions in the manufacturing sector. During conventional fusion welding, a heat source is used to join materials by melting the materials and solidification. Currently, lightweight Aluminum alloy are greatly used in the aerospace industry even at cryogenic temperature. When conventional welding (fusion welding) is used to join lightweight aluminum alloys, weld defects such as porosity or crack occurs. Therefore a solid-state joining process, Friction- stirwelding (FSW) welding is used to join lightweight aluminum alloy. The FSW process was invented by The Welding Institute less than three decades ago [1]. During FSW the lack of filler material addition generally used in the conventional fusion arc welding makes having defect free FSW consistently possible. Also, during FSW, favorable phase transformations occur whereas in fusion welding usually unfavorable phase transformations occur. As a result FSW welding joints exhibit superior mechanical characteristics compared to conventional fusion welding. During the FSW process, a rotating pintool with a shoulder is inserted into the butt of the workpiece and then translates along the welding line as shown in Fig. 1.

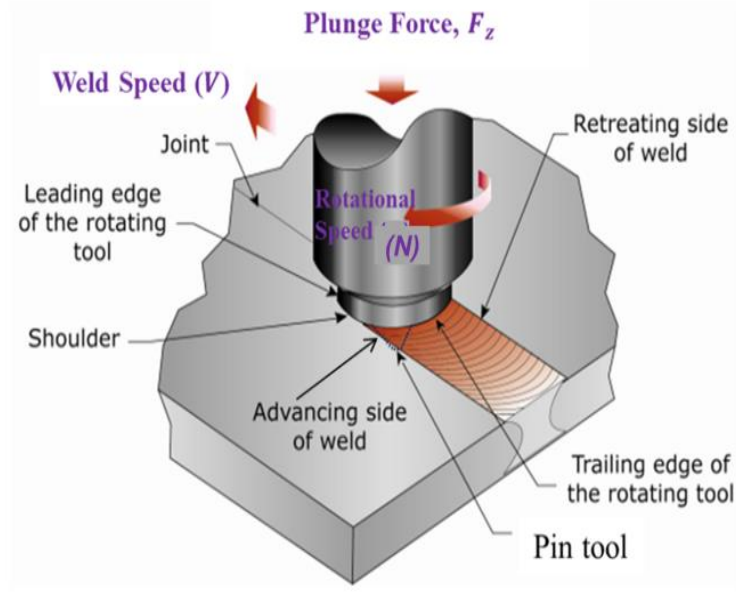

Fig. 1 Schematic representation of Friction-Stir-Welding (FSW) process [2] 
During FSW heat energy is generated due to friction between the pintool/workpiece and large plastic deformations for material stirring in the nugget zone and joining the workpiece. So far, several numerical models have been developed to explore the heat generation mechanism during FSW [3-7]. However, contact condition between the pintool and the workpiece is still not fully revealed or explained sufficiently; and hence there is still several unresolved questions relating to whether the contact condition is sticking or sliding.

In FSW, there are two extreme contact conditions occur, (a) full stick condition (pintool and workpiece material have the same velocity), and (b) full sliding condition (pintool and workpiece material have different velocities). Some authors have concluded that sticking condition dominates during FSW. For example, a Computational Fluid Dynamics (CFD )based visco-plastic model was developed by Ulysse [8] for FSW by considering full sticking condition. Another CFD based FSW model [9] considered a full sticking condition. Some authors $[10,11]$ have developed a thermal model of FSW considering sliding condition even though the slipping condition prevails.

The work of Schmidt et al. [12] and Gerlich et al. [13] considered contact between pintool/workpiece during the weld processing as a partially sticking/sliding condition as the weld progresses. In the work of Heurtier et al. [14] both kinematical and thermal modeling are combined heat generation both from sticking and sliding conditions was considered. However, in the work of Heurtier et al. [14] sticking and sliding conditions were uncoupled; as coupling both of the sources is considered to be complex. Schmidt et al. [15] used a contact state variable, $\delta$ which represents slip rate between the tool and the workpiece (when, $\delta=0$ : full sliding ; $\delta=1$ : full sticking; and $0<\delta<1$ : partial sliding/sticking). A 3D CFD model was developed by Nandan et al. [16] which considered partial sticking condition at tool shoulder and full sticking condition at the pin tool interface , the numerically simulated temperature results are in good agreement with the experimental result. Another model was established by Su et al. [17], where the friction coefficient and the slip rate were determined by using the experimental pintool torque and axial force are used to determine friction coefficient and slip rate. Different contact models have been used in the published literature to model the stick/slip condition at the interface between the pintool and the workpiece for FSW processing. Several researchers [5, 18-20] used the Coulomb friction model in their thermomechanical modeling of FSW. The influence of the Norton and Coulomb friction model on FSW has been compared in the work of Assidi et al. [21] where they showed that utilization of Norton friction model for FSW failed to obtain appropriate temperature profile for the pintool. Moreover, welding forces obtained by Norton friction model is significantly higher than experimentally observed values. Then again, results got utilizing the Coulomb friction model are close to experimentally welding forces. However, the shortcomings of using the Coulomb model are that the friction shear stress cannot be increased without setting an upper limit which causes shear failure of the material. To overcome Coulomb model's limitation, various researchers [22-25] used the modified Coulomb's friction law to model FSW and accounted for the stick/slip condition between pintool/workpiece.

Ongoing work done by Shi et al.[26], built up a 3D model to which is able to capture heat generation, temperature field and material flow in reverse dual rotation friction stir welding process. The reverse rotation of the shoulder and the tool pin is the dominant contributor to the heat generation rate. The temperature profile from the model and the experimental results matches well. Another work done by Waheed et al. [27] modeled FSW with various tool pin profiles in friction stir welding. The models are produced including welding process as a blend of unadulterated sliding and unadulterated sticking conditions. From the acquired outcomes it very well may be seen that, the measure of heat generation is relative to the edges in the pin profiles. The anticipated outcomes likewise demonstrate a decent concurrence ith the exploratory outcomes. A CFD model was developed by Zhang et al. [28], to research the spatial dispersion of frictional heat flux and plastic deformation amid the FSW of AA2024-T4. In their work, the circulation of frictional heat motion at the welding apparatus/workpiece interface is represented using Gaussian heat source model. Later work done by Sun et al. [29] developed a three dimensional model which determine heat generation at the workpiece interface utilizing interfacial frictional pressure. The model computes interfacial frictional pressure straightforwardly dependent on the pressure of the material nearby the pintool workpiece interface and the von mises yield basis, the interfacial friction stress is then connected with the temperature. The interfacial grinding pressure diminishes continuously with increment in temperature.

From critical literature review, it is clear that few studies have been conducted to compare the effect of process parameters on the Coulomb and the modified Coulomb friction model. Only in the work of Zhang et al. [30], the Coulomb model and the modified Coulomb model has been compared to study the effect on "temperature" and "material flow prediction". From the work of Zhang et al. [30] it can be seen that at low pintool rotational speed, no obvious difference is observed between the two models in the simulation of FSW process. Also at higher pintool rotation speed, the classical Coulomb friction model fails to finish the simulation whereas, the modified Coulomb model can successfully complete the simulation. This is because the decrease of the friction stress leads to a dynamic effect caused by the welding pintool. However, in the work of Zhang et al. [30], only a single weld schedule have been analyzed to observe the effect of process parameters on the friction and the plastic energy.

Therefore the focus of this paper is to compare the Coulomb and the modified Coulomb friction models by studying the effect of process parameters. The models used in the current work will help understand how the process parameters can influence temperature, friction and plastic energies. During FSW, there are several interactions between process parameters known to affect the overall quality of the weld that needs to be considered, such as:-pintool rotational speed, welding speed, and the plunge rate 
$[25,31]$. The present research work is divided into two parts; in part 1 , we will compare the effect of pintool rotational speed on the Coulomb and the modified Coulomb model and in part 2, we will compare the effect of welding speed and plunge rate on the Coulomb and the modified Coulomb model.

The objectives of this study

The main objective of the present work is mainly two folds: First, to develop thermomechanical model using the Coulomb and the modified Coulomb models to estimate the heat generation during FSW and to compare the temperature profiles from all the four models with the FSW experimental schedule of Aluminum AA2219 alloy to demonstrate the validity of these models. Secondly to perform a parametric study by varying important weld process parameter- rotational speed and analyze the response from different models for the purpose of understanding of energy generation of FSW. The pintool rotational speed was chosen to be varied from $200 \mathrm{rpm}$ to $450 \mathrm{rpm}$ based on earlier experimental investigations by our research group [32].

\section{Arbitrary Lagrangian-Eulerian formulation}

\section{II.NUMERICAL MODEL}

Numerical simulation of FSW is always complex as a result of the high deformation underneath the pin tool. Eulerian formulation can be used for FSW modeling, however Eulerian formulation has shortcoming in the prediction of the contact surface between pin tool and workpiece. Lagrangian formulation does not encounter these difficulties and allows computing residual stresses at the weld plate. However, it is intrinsically difficult to model large deformation by Lagrange formulation which requires complicated remeshing. The Arbitrary Lagrangian-Eulerian (ALE) technique combines the advantages of both the Lagrangian and the Eulerian approaches which is suitable for large deformation problems. The benefit of using Arbitrary Lagrangian-Eulerian (ALE) method is that it allows node points to be moved randomly which allows the material and mesh to move independently.

\section{Constitutive model of the material}

In the developed FSW model, the plate that is used for welding is considered as a solid ductile material with the capability of simulating large strain, high deformation, and Johnson-Cook strain hardening effect. During FSW, the elastic and plastic behavior are highly rate- dependent, therefore of the plate's elastic and plastic material characteristics are modeled as rate- dependent. The Johnson-Cook plasticity model [33] is commonly used for large strains, high strain rates and high temperatures. An expression of the Johnson-Cook model can be represented by the following Equation (1),

$$
\sigma_{y}=\left(A+B\left[\bar{\varepsilon}^{p l}\right]^{n}\right)\left(1+\operatorname{cln} \frac{\dot{\varepsilon} \dot{p l}}{\varepsilon_{0}}\right)\left(1-\left(\frac{T-T_{r e f}}{T_{\text {melt }}-T_{\text {ref }}}\right)^{m}\right)
$$

As mentioned earlier, there was no heat flux acts as a heat source in the present work; on the other hand heat generation in the model was due to friction and plastic deformation among the interface of the pintool and the workpiece. Where, $\sigma_{y}$ is the yield stress, $\bar{\varepsilon}^{p l}$ the equivalent plastic strain, $\varepsilon_{p l}^{\cdot}$ the effective plastic strain rate, and $\dot{\varepsilon}_{0}$ the normalizing strain-rate. Here, $A, B, C, n$, and $m$ are material/test constants, and $T_{m e l t}, T_{r e f}$ are the melting and reference temperatures, respectively.

Material properties of the AA2219 used for Johnson-Cook model in the current study is listed in Table 1.

Table 1 Johnson- Cook Material Plastic Model input [34]

\begin{tabular}{|c|c|c|c|c|c|}
\hline $\begin{array}{c}\mathrm{A} \\
(\mathrm{MPa})\end{array}$ & $\begin{array}{c}\mathrm{B} \\
(\mathrm{MPa})\end{array}$ & $\mathrm{n}$ & $\mathrm{m}$ & $\begin{array}{c}\text { Melting temperature } \\
\left({ }^{\circ} \mathrm{C}\right)[35]\end{array}$ & $\begin{array}{c}\text { Reference temp } \\
\left({ }^{\circ} \mathrm{C}\right)\end{array}$ \\
\hline 369 & 684 & 0.73 & 1.7 & 543 & 25 \\
\hline
\end{tabular}

To represent yield conditions, von Mises yield criterion has been used in the present work. The von Mises yield criterion is expressed by Equations (2) and (3)[36],

$$
f\left(\sigma, \sigma_{y}\right)=\sigma_{e}-\sigma_{y}=0
$$

$$
\text { where, } \sigma_{e}=\text { von Mises effective stress }=\sqrt{\frac{3}{2}\left(\sigma: \sigma-\frac{1}{3} \operatorname{Tr}(\sigma)^{2}\right)}
$$

$\operatorname{Tr}=$ Tresca criterion, $\sigma=$ Stress

The load increment in the model is obtained using flow rule. An associative flow rule is used in the current model, which is represented by Equation (4) [34]; 


$$
d \varepsilon^{p l}=d \bar{\varepsilon}^{p l} \frac{\partial f(\sigma)}{\sigma}
$$

Where, $\varepsilon^{p l}=$ Plastic strain, $d \bar{\varepsilon}^{p l}=\sqrt{\frac{2}{3} d \varepsilon^{p l} \cdot d \varepsilon^{p l}}$. If the deviatoric stress tensor $S$ and von Mises yield function are used, the equivalent expression of Equation (5) can be obtained [34],

$$
d \varepsilon^{p l}=\frac{3 S}{2 \bar{\sigma}} d \bar{\varepsilon}^{p l}
$$

Elastoplastic conduct is portrayed by the strain rate or strain increment into elastic and plastic parts as shown in Equation (6) [34],

$$
\dot{\varepsilon}=\dot{\varepsilon}^{e l}+\dot{\varepsilon}^{p l}
$$

Jaumann stress rate is employed to define the material behavior; the rate of stress is purely due to the elastic part of the strain rate and shown using Hook's law by using Equation (7) [34],

$$
\dot{\sigma}=\lambda \operatorname{trace}\left(\dot{\varepsilon}^{e l}\right) \mathrm{I}+2 \mu \dot{\varepsilon}^{e l}
$$

where $\operatorname{trace}\left(\dot{\varepsilon}^{e l}\right)=\dot{\varepsilon}_{i i}^{e l}=\sum_{i=1}^{n} \dot{\varepsilon}_{i i}^{e l}, \lambda$ and $\mu$ are elastic constants.

After integration, Equation (7) becomes Equation (8),

$$
\Delta \sigma=\lambda \operatorname{trace}\left(\Delta \varepsilon^{e l}\right) \mathrm{I}+2 \mu \Delta \varepsilon^{e l}
$$

The von Mises yield function,

$$
\sqrt{\frac{3}{2} S: S}-\sigma_{y}=0
$$

where $S: S=S_{i j} S_{i j}$, and $\sigma_{y}$ is the uniaxial yield stress, which is defined as a function of equivalent plastic strain, strain rate and temperature. $S$ is the deviatoric stress and $p$ the hydrostatic pressure is represented in Equation (10) and (11),

$$
\begin{gathered}
S=\sigma+p I \\
p=-\frac{1}{3} \operatorname{trace}(\sigma)
\end{gathered}
$$

The equivalent plastic strain is given by Equation (12) and Equation (13),

$$
\begin{gathered}
\bar{\varepsilon}^{p l}=\int_{0}^{t} \dot{\bar{\varepsilon}}^{p l} d t \\
\dot{\bar{\varepsilon}}^{p l}=\sqrt{\frac{2}{3} \dot{\varepsilon}^{p l}: \dot{\varepsilon}^{p l}}
\end{gathered}
$$

and the plastic flow is expressed in Equation (14),

\section{Validation Experiments}

$$
\dot{\varepsilon}^{p l}=\frac{3}{2} \frac{S}{\sigma_{y}} \dot{\bar{\varepsilon}}^{p l}
$$

Fig. 2 represents the experimental setup of the FSW process used to validate the numerical model developed in this study. ISTIR- PDS- FSW machines were used to weld the plates. The workpiece was Al-AA2219 for Aluminum alloy which has a thickness of $8.13 \mathrm{~mm}$. During FSW, a tapered screw pin thread is used as a pintool. The pintool shoulder diameter is $30 \mathrm{~mm}$ and the pin nib diameter is $10 \mathrm{~mm}$. The height of the pintool shoulder and pin nib are $4 \mathrm{~mm}$ and $6 \mathrm{~mm}$, respectively. The pintool is tapered at an angle equal to $20^{\circ}$.At the time of the welding, temperature are measured from the surface of the workpiece using both thermocouple and thermographer [32] simultaneously. 


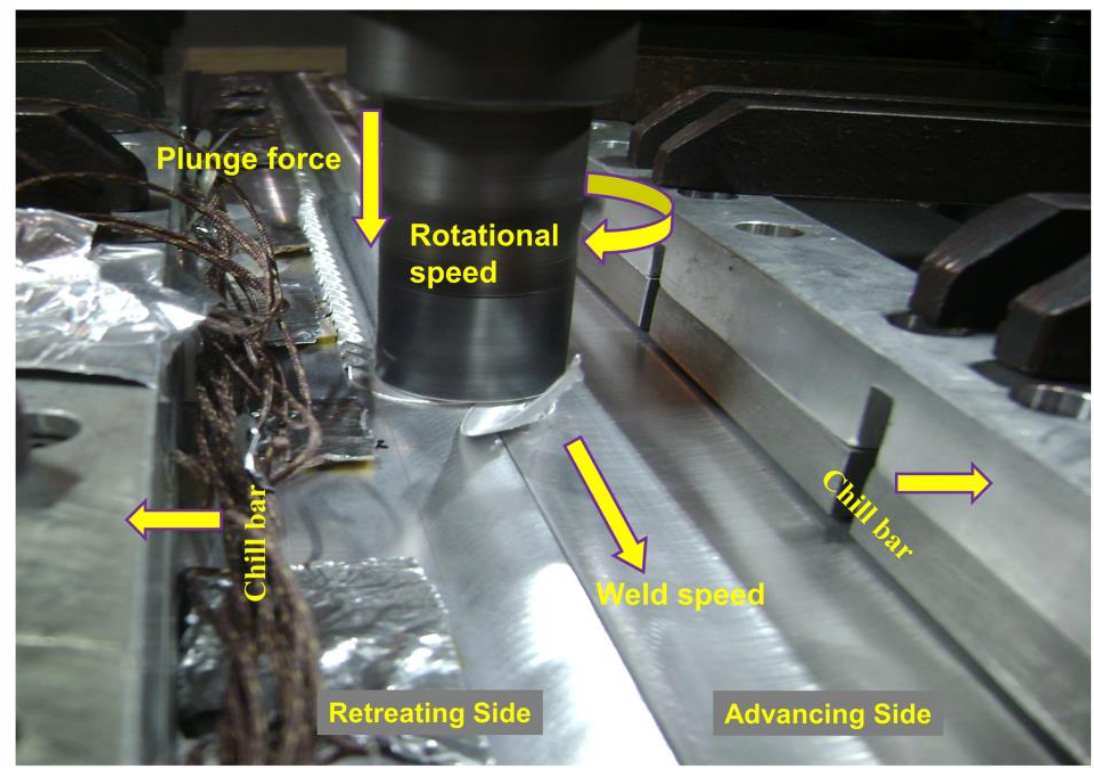

\section{FSW finite element model}

Fig. 2 Experiment setups and process parameter of FSW [24]

Finite Element Analysis (FEA) software, ABAQUS/Explicit has been used to model the numerical simulations presented in this study. The pintool used in the experimental study is made of steel. In present work, the pintool is assumed to be isothermal and rigid rather than deformable to avoid unnecessary computational complexities. The pintool shoulder diameter is $30 \mathrm{~mm}$ and shoulder height is $4 \mathrm{~mm}$. The pin nib diameter is $10 \mathrm{~mm}$ and its height is $6 \mathrm{~mm}$ (Fig. 3(b)) with a tapered angle of $20^{\circ}$. A reference point is used to control the movement of the pintool. The reference point has the capability of translation, rotation, and thermal degrees of freedom. The plate is modeled using an eight-noded 3-D temperature displacement coupled element, C3D8RT. This type of element has 8-node tri-linear displacement and temperature degree of freedom, and reduced integration with hourglass control. In this model, a single-plate is modeled rather than two plates to avoid contact complexities. The entire plate was assigned as an adaptive domain which allows the mesh and the material to be moved independent of each other. The top surface of the workpiece is considered as a sliding surface, where the mesh follows the material movement in the normal direction to the surface and moves independently of the underlying material in the tangential direction. The original plate length and width have been truncated, but the actual thickness was maintained in order to reduce simulation time. This enables the simulation to capture the behavior of the steady-state portion of the FSW process successfully without the need to simulate the entire steady-state region. The width of the workpiece in the developed model was decreased by trimming $112 \mathrm{~mm}$ from the plate's boundaries which is at a distance from the weld line. The eliminated parts of the plate have hardly any boundary effect on welding procedure. The dimension of the modeled plate is length: $80 \mathrm{~mm}$; width: $40 \mathrm{~mm}$ and thickness: $8.128 \mathrm{~mm}$. In the model, the workpiece is considered as a solid ductile material whose constitutive model is capable of large strain, high deformation, and Johnson-Cook strain hardening effect. The workpiece's material behavior was considered to be dependent on the rate of strain, which was determined after reviewing the pintool rotational speed and travel speed of the FSW schedules covered in this research. As referenced before, there was no external heat source input applied to the model; rather heat generation in the model was a result of friction work between the tool and the workpiece interface. The meshed model of the pintool (Fig. 3(a) has 204,800 nodes and 25,600 elements.

(a)

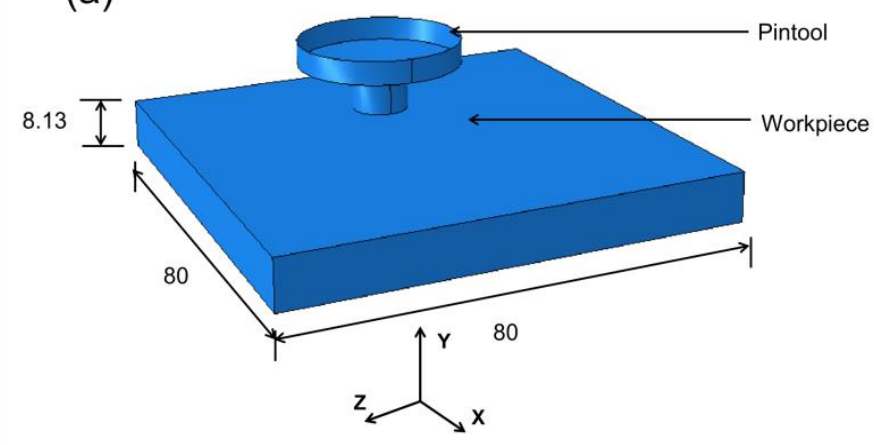

(b)

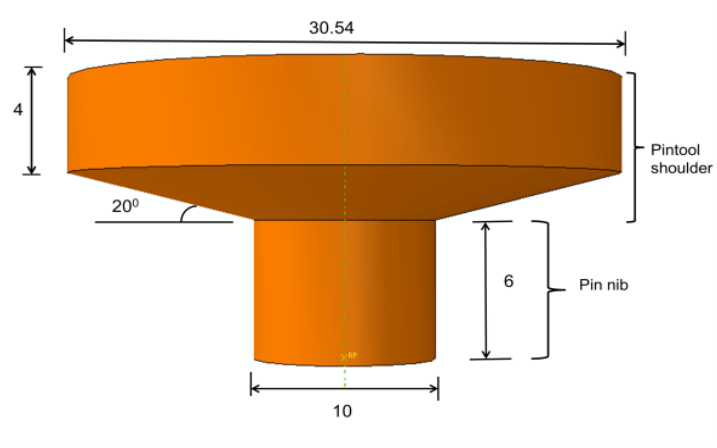

Fig. 3 (a) The geometry model for FSW process; and (b) Geometry of the pintool 
The FSW process has three steps, namely: plunge, dwell, and travel. In the plunge step, the pintool descends towards the plate while rotating. After the initial penetration of the pin nib at the workpiece, the pintool rotates to increase the temperature close to the melting temperature during the dwell step. The travel step is the last step where the pintool is traversed along the joint line. Time steps and the boundary conditions used in the modeling are listed in Table 2 . The pintool had a plunge rate of $0.4 \mathrm{~mm} / \mathrm{s}$ and plunging occurs for 15.2 seconds. A more detail on current FSW model can be found in our previous published work [25].

Table 2 Simulation details for three modeling steps

\begin{tabular}{llc}
\hline Stage & Time Step & Boundary condition \\
\hline Plunging & $15.2 \mathrm{~s}$ & Displacement along y-axis, \\
& & Rotation along y-axis \\
Dwelling & $5 \mathrm{~s}$ & Rotation along y-axis \\
Traversing & $20 \mathrm{~s}$ & Rotation along y-axis \\
& & Movement along x-axis \\
\hline
\end{tabular}

In the present work, equation used to calculate frictional energy dissipation is given by Equation (15),

$$
\mathcal{R}=\tau \dot{\gamma}
$$

where, $\tau=$ stress due to friction and $\dot{\gamma}=$ slip rate. The heat energy distributed on the pintool's shoulder surface and workpiece's top surface is calculated by Equation (16),

$$
P_{A}=f \eta \mathcal{R} \text { and } P_{B}=(1-f) \eta \mathcal{R}
$$

where, $\eta=$ fraction of dissipated energy; $f=$ the weighting factor; $P_{A}=$ heat flux into the workpiece top surface;

$P_{B}=$ heatflux into the bottom surface of the pintool.

The heat generated by plastic energy dissipation is calculated by Equation (17),

$$
\mathcal{F}^{p l}=\eta_{A} S \varepsilon_{p l}^{\cdot}
$$

where, $\eta_{A}=$ user defined factor, $S=$ deviatoric stress, $\varepsilon_{p l}=$ rate of plastic straining, $\mathcal{F}^{p l}=$ plastic energy dissipation energy.

In present work, $90 \%$ of frictional and plastic energy is assumed transformed into the heat energy [3].

\section{Choice of Friction coefficient in FSW model}

The selection of friction coefficient between the pintool/workpiece interfaces is important in FSW heat generation. During FSW, the temperature at pintool/workpiece interface of the alloys gets close to the temperature of solidus, which softens the pintool/workpiece interface and reduces the friction. In the work of Midling and Grong [37], it is suggested that the friction between Aluminum and mild steel should have a coefficient value of 0.5 for sticking condition. Results obtained in the work of Ashby et al. [38] suggested that steel sliding on Aluminum results in a friction coefficient of 0.25 in dry sliding test at ambient temperature. Soundarararjan et al.[23] found that the friction coefficient varies between 0.4 and 0.5 according to the welding condition. A constant value of friction coefficient 0.3 was used by Schmidt and Hattel [19]. Numerous elements such as temperature, contact geometry, and applied force affect the friction coefficient. Zhang et al. [6] conducted a detailed study on the factors affecting friction coefficient for FSW process. The research work of Zhang et al.[6] showed that the friction coefficient significantly depends on temperature. Consequently, a temperature-dependent friction coefficient analysis that varies in the range between 0.2 and 0.3 [39] was used in the analysis presented in this paper. The value of friction coefficient in the current analysis are listed in Table 3, which shows that as the temperature rises, the friction coefficient is constant up to $300^{\circ} \mathrm{C}$. However, after the temperature reaches $300^{\circ} \mathrm{C}$, the friction coefficient starts decreasing. Zhang et al.[6] explained the choice of friction coefficient in the flowchart shown in Fig. 4 below.

Table 3 Friction coefficient (temperature dependent) used in current work

\begin{tabular}{cc}
\hline Temperature $\left({ }^{\circ} \mathrm{C}\right)$ & Friction coefficient \\
\hline 25 & 0.30 \\
300 & 0.25 \\
420 & 0.20 \\
543 & 0.01 \\
\hline
\end{tabular}




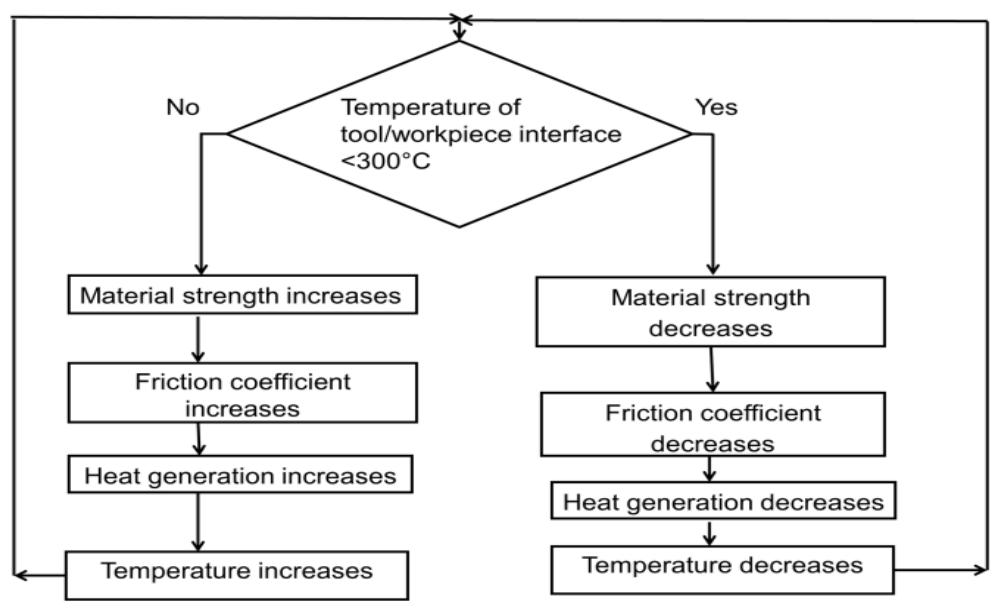

\section{Material properties}

Fig. 4 Explanation for choice of friction coefficient used in current study[6]

Aluminum-AA2219 material properties (Temperature dependent Elastic Modulus, thermal conductivity, Specific heat capacity) are shown in Figs. 5-7.

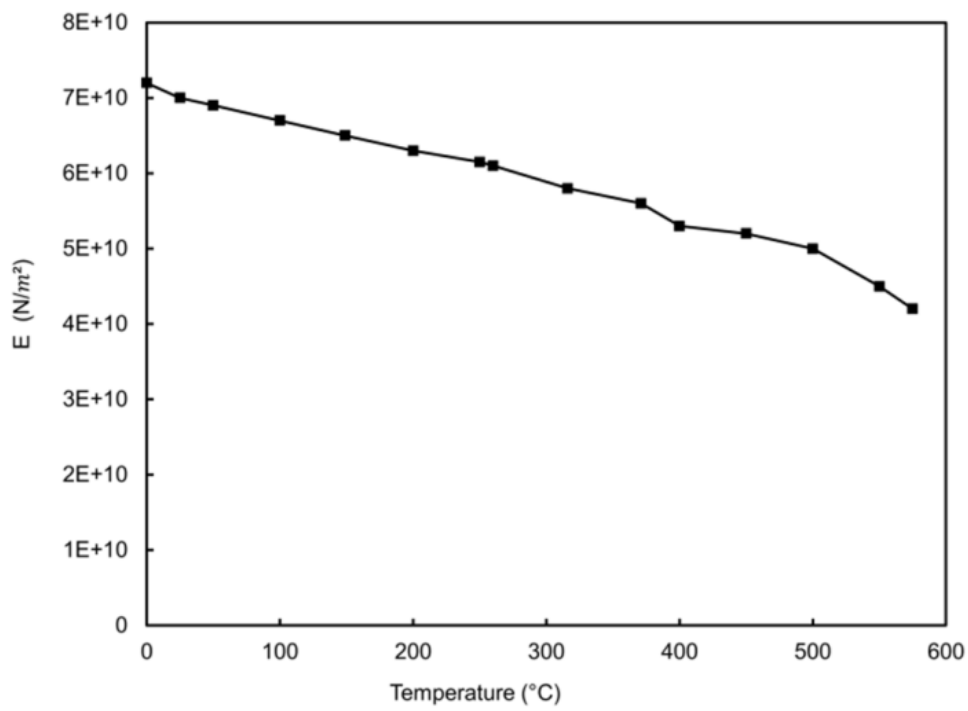

Fig. 5 Temperature dependent elastic modulus of Aluminum [40]

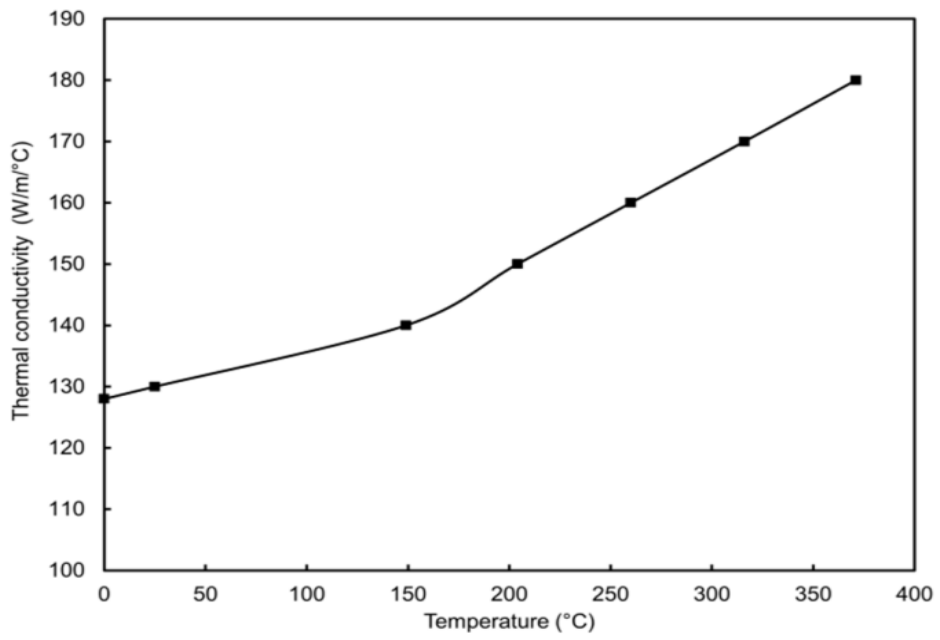

Fig. 6 Temperature dependent thermal conductivity of Al-AA2219 [41] 


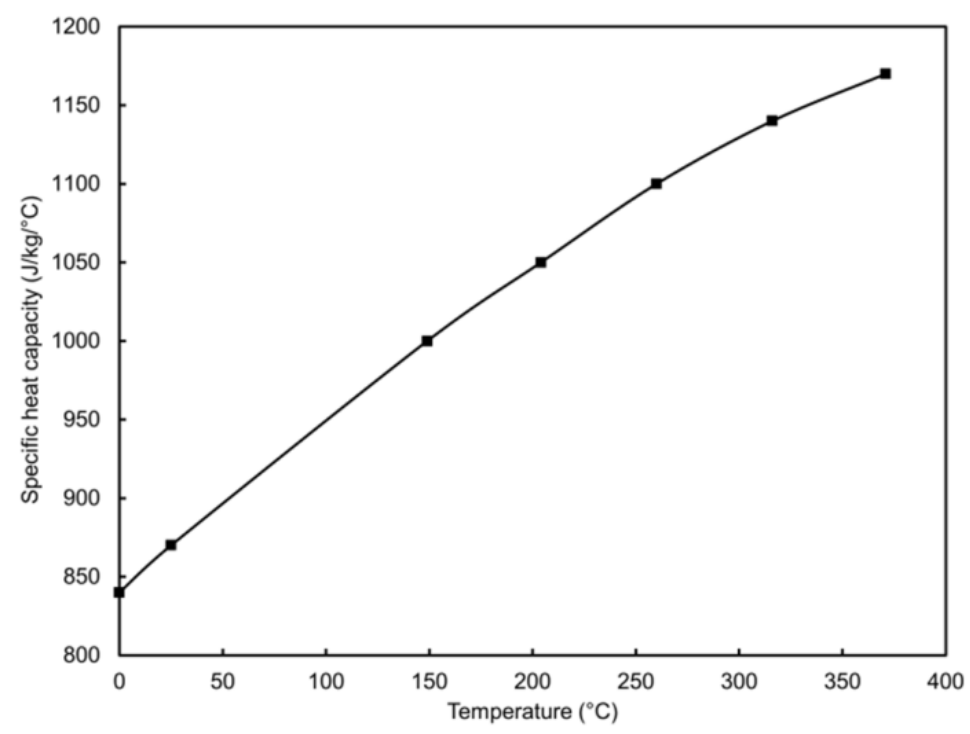

Fig. 7 Temperature dependent in specific heat capacity of Al-AA2219 [41]

As mentioned earlier, the FSW pintool has a temperature degree of freedom. The pintool-workpiece interaction causes the pintool to absorb a portion of the generated heat. The bottom surface of the pintool was allocated a heat capacitance value of $350 \mathrm{~W} / \mathrm{m}^{2}$.

\section{Thermal Boundary Condition}

Fig. 3 shows the physical model of the setup. In the model the initial temperature is set to $25^{\circ} \mathrm{C}$. The heat exchange between the top surface of the workpiece and the shoulder involves consideration of convective heat transfers. The initial temperature boundary can be expressed as shown in Equation (18);

$$
T(x, y, z, t)=T_{i}
$$

The equation for energy conservation during FSW process expressed by Equation (19);

$$
\rho c_{p} \frac{\partial T}{\partial t}=\frac{\partial}{\partial x}\left[k_{x} \frac{\partial T}{\partial x}+k_{y} \frac{\partial T}{\partial y}+k_{z} \frac{\partial T}{\partial z}\right]+Q
$$

where, $c_{p}$ is the specific mass heat capacity, $\rho$ is the material density, $k$ is the thermal conductivity $\left(k_{x}, k_{y}, k_{z}\right.$ are the heat conductivity in $x, y, z$ directions), $Q$ is the heat generation and $T$ is the absolute temperature.

Energy balance Equation (19) can be expressed as Equation (20);

$$
C(t) \dot{T}+K(t) T=Q(t)
$$

where, $T$ is the nodal temperature vector, $\dot{T}$ is the temperature derivative respect to time (i.e. $\left.\frac{d T}{d t}\right), K(t)$ is the time dependent conductivity matrix, $C(t)$ is the time dependent capacitance matrix and $Q(t)$ is heat vector with respect to time.

The heat convection is a major source for loss of heat in the plate during FSW. The heat loss from side surface and top surface of the plate is calculated using Equation (21);

$$
K{\frac{\partial T}{\partial z_{\text {side }}}}=h_{c}\left(T-T_{a}\right)
$$

where, $T$ represents absolute temperature of the work piece, $T_{a}$ ambient temperature and $h_{c}$ convection coefficient.

During the experiment (see Fig. 2), the presence of the chill bar helps to clamp the workpiece. A high heat transfer coefficient $100 \mathrm{~W} / \mathrm{m}^{2}$ has been assigned on the top surface of the workpiece caused by chill bar [24]. Heat loss from the side surface of the plate is calculated using, a heat transfer coefficient equal to $30 \mathrm{~W} / \mathrm{m}^{2}$ is assigned convection from aluminum to air [42]. 
At the bottom of the plate, a support plate is utilized to counter the plunge force. The support plate also acts as a high heat sink during welding. Therefore, a high heat transfer coefficient is used to model the heat transfer from support plate. At the bottom surface of the workpiece, the heat is transferred into the support plate and is given by Equation (22),

$$
K{\frac{\partial T}{\partial y_{\text {bottom }}}}=h_{b}\left(T-T_{a}\right)
$$

where, $h_{b}$ represents convective heat transfer coefficient from support plate. The value of $h_{b}$ is calibrated to match the experimental result to avoid complexity associated with determining contact conditions between the workpiece and the support plate. The value of $h_{b}$ was found to be $100 \mathrm{~W} / \mathrm{m}^{2}$ for the justification FSW experimental setup has been shown in Fig. 8 .

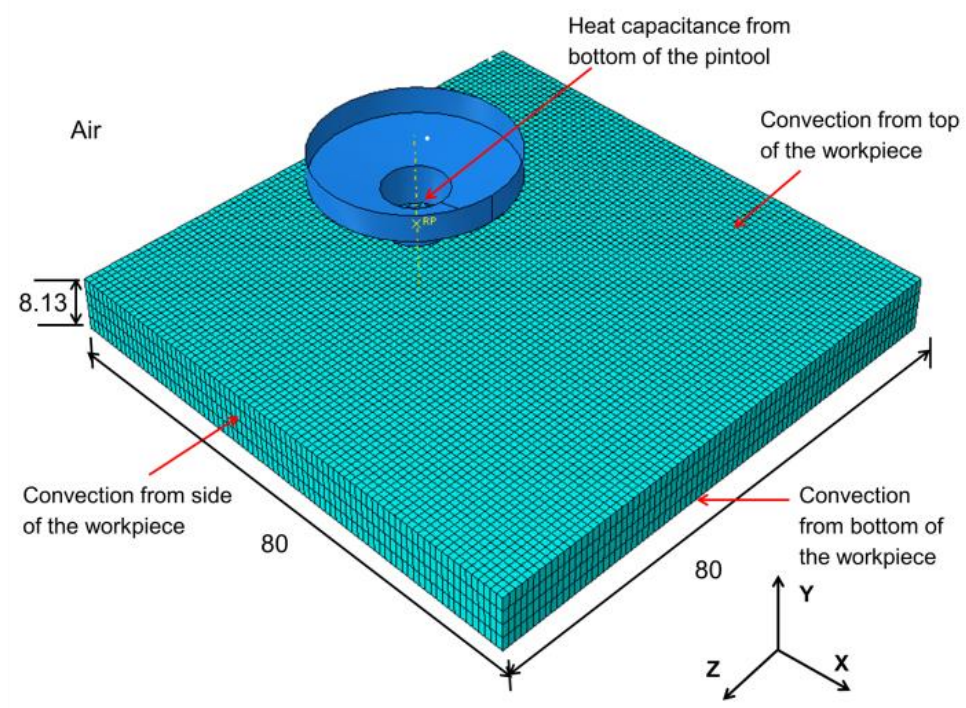

Fig. 8 The meshed model and boundary conditions of thermal study (all dimensions are in millimeter)

\section{Mechanical Boundary Condition}

Fig. 9 shows mechanical boundary conditions of the workpiece. The workpiece bottom surface is fixed in the normal direction as shown in Fig. 9 [24] as represented in Equation (23) .

$$
U_{y}=0 \quad \text { at } y=0
$$

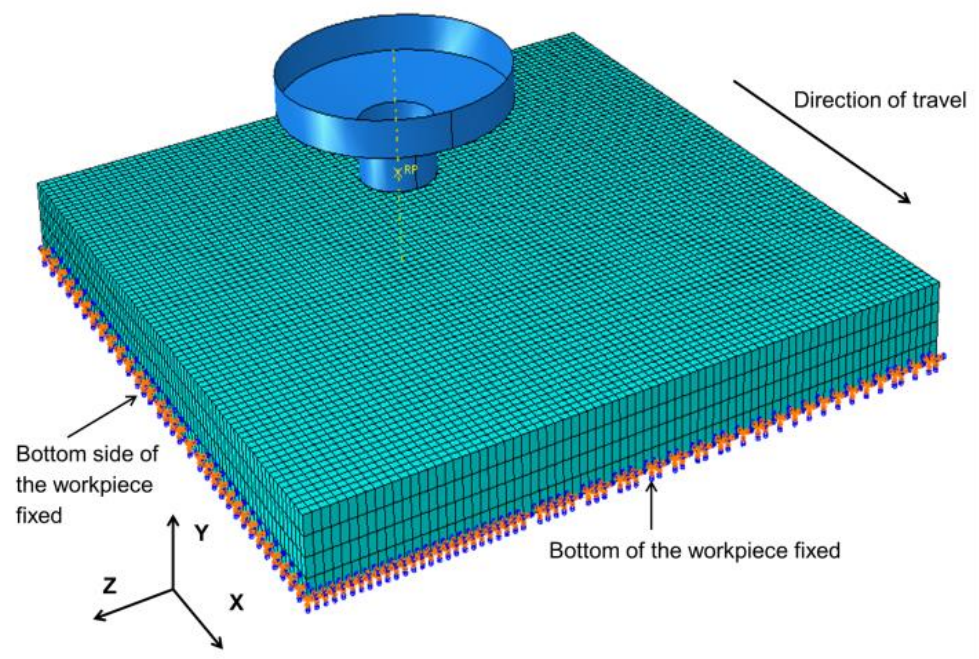

Fig. 9 Mechanical boundary conditions of workpiece 


\section{Contact properties}

During FSW, sticking or sliding occurs between the materials in contact (workpiece and pintool) depending upon the contact shear stress. While sticking, material near the surface adheres to the pintool. The velocity dissimilarity among stationary material and materials moving along the tool causes shearing action.

The determination in the contact friction stress is different in the two contact models: Coulomb friction law and modified Coulomb friction law.

According to Coulomb friction model, no relative motion occurs if the equivalent frictional stress, $\tau_{e q}$, is less than critical stress, $\tau_{c r i t}$. The equivalent friction stress, $\tau_{e q}$ can be defined by Equation (24),

$\tau_{1} \& \tau_{2}=$ Two orthogonal components of shear stress

$$
\tau_{e q}=\sqrt{\tau_{1}^{2}+\tau_{2}^{2}}
$$

In Coulomb Friction Law, $\tau_{\text {crit }}$ can be expressed as a function of the friction coefficient, $\mu$, and the contact pressure, $P$, as given in Equation (25),

$$
\tau_{\text {crit }}=\mu p
$$

where,. The fundamental assumption is that slip occurs when, $\tau_{e q}=\tau_{c r i t}$.

In a modified Coulomb Friction Law, the critical friction stress is limited by capping the critical stress, $\tau_{c r i t}$, to a maximum limit as shown in Equation (26),

$$
\tau_{c r i t}=\min \left(\mu p, \tau_{\max }\right)
$$

In the current analysis, the distortion energy criterion, $\tau_{\max }=\frac{\sigma_{y}}{\sqrt{3}}=0.58 \sigma_{y}$ is used to identify stick/slip criterion.

Based on modified Coulomb's model, when the equivalent shear stress, $\tau_{e q}$, is less than the maximum frictional stress, $\tau_{\max }$, a sticking condition is modeled in current analysis. Conversely, when the equivalent shear stress, $\tau_{e q}$, exceeds $\tau_{\text {max }}$, the contact and the target surface will slide relative to each other, (i.e. sliding condition is modeled). Contact shear stress vs. contact pressure for sticking and sliding conditions are illustrated in Fig. 10.

$\left\|\tau_{\text {contact }}\right\| \leq \tau_{\max } \rightarrow$ (Sticking); $\left\|\tau_{\text {contact }}\right\| \geq \tau_{\max } \rightarrow$ (Sliding);

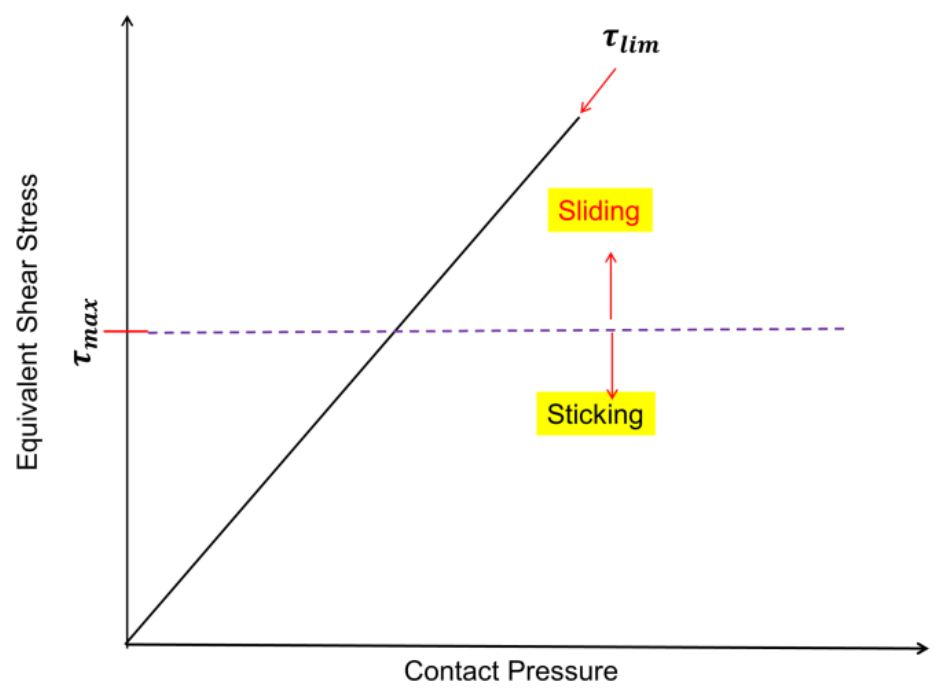

Fig. 10 Modified Coulomb's Law [24]

\section{III.NUMERICAL MODELS CONSIDERED IN THIS STUDY}

There are four numerical models presented in this paper. These four different models are: (i) C- model: Coulomb contact model with constant friction coefficient; (ii) $\mathrm{Cm}$ - model: modified Coulomb contact model with constant friction coefficient; (iii) $\mathrm{Cmft}$ model: Modified Coulomb contact model with temperature dependent friction coefficient; and (iv) Cmftwt- model: Workpiece 
temperature dependent material properties along with modified Coulomb contact model with temperature dependent friction coefficient.

\section{C- model}

In this case, the workpiece is considered to be elasto-plastic, and the material properties of the workpiece are considered to be temperature independent. Classical Coulomb friction model is used for defining the contact condition between the pintool/workpiece assuming a constant friction coefficient, $\mu=0.3$ was used in the model.

\section{Cm- model}

In this model, the workpiece is considered elastic plastic and the material properties of the workpiece are considered to be temperature independent. In this case, modified Coulomb friction along with a constant friction coefficient, $\mu=0.3$ is used in the contact model.

\section{Cmft- model}

In this model, the workpiece is also considered to be elasto-plastic, and its material properties are temperature independent. In the model, modified Coulomb friction has been used to model the pintool/workpiece contact conditions. The friction coefficient is considered to be temperature dependent (see Table 3 ) in this case.

\section{Cmftwt- model}

In this case, the workpiece is considered to be elastoplastic, and the workpiece material properties are considered to be dependent upon temperature. In the model, modified Coulomb friction has been used to model the contact between pintool/workpiece. Also, the friction coefficient has been assumed to be temperature dependent as seen in Table 3 .

Table 4 summarize all the FSW models used for analysis in the present work.

Table 4 Comparison of different model properties used in the current analysis

\begin{tabular}{|c|c|c|c|}
\hline Model name & Workpiece material properties & Friction Model & Friction coefficient \\
\hline C- model & Temperature independent & Coulomb friction model & Constant friction coefficient, $\mu=0.3$ \\
\hline Cm- model & Temperature independent & Modified Coulomb friction model & Constant friction coefficient, $\mu=0.3$ \\
\hline Cmft- model & Temperature independent & Modified Coulomb friction model & $\begin{array}{c}\text { Temperature dependent friction } \\
\text { coefficient(Value from Table 3) }\end{array}$ \\
\hline Cmftwt -model & $\begin{array}{c}\text { Temperature dependent(Value from } \\
\text { Fig. 5-7) }\end{array}$ & Modified Coulomb friction model & $\begin{array}{c}\text { Temperature dependent friction } \\
\text { coefficient (Value from Table 3) }\end{array}$ \\
\hline
\end{tabular}

\section{IV.MODEL VALIDATION}

In the present work, temperature readings from the workpiece surface during welding of Aluminum AA2219 alloy plates have been used for validation. The weld schedule used for thermal validation has rotational speed, $N=350 \mathrm{rpm}$, weld Speed, $\mathrm{v}=1.27$ $\mathrm{mm} / \mathrm{s}$, and a plunge rate of $0.4 \mathrm{~mm} / \mathrm{s}$. During welding, temperature was measured from the top surface of the workpiece using both K-type thermocouple and FLIR thermovision A40 thermographer simultaneously. Initially, emissivity values for aluminum and steel were taken from the literature. Prior to the experiments, both systems (K-type thermocouple and thermograph) were calibrated by taking measurements from a calibrated hot plate at different increments (0 to $300 \mathrm{C}$ ). Furthermore, different materials such as aluminum, steel and black heat tape were used on the hot plate to ensure the material matched the set hot plate measurement. The arrangements of the thermocouples are shown in Fig. 11

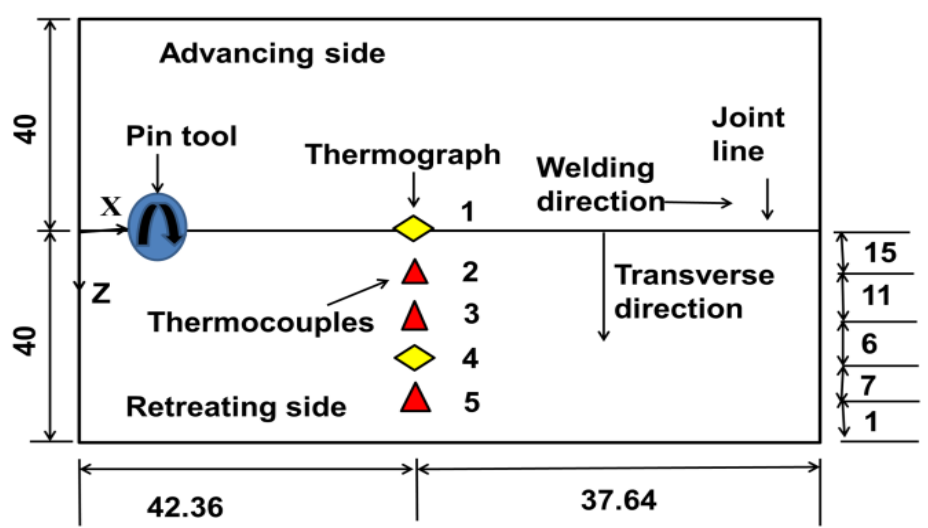

Fig. 11 Arrangements of the thermocouples (attached to the surface) and thermographer (dimensions unit millimeter) 


\section{Temperature validation along longitudinal direction}

Fig. 12 shows the comparison for temperature field at the thermocouple location number 3 in the direction of weld for different models. The peak temperature at location 3 is $362{ }^{\circ} \mathrm{C}, 369.09^{\circ} \mathrm{C}, 361^{\circ} \mathrm{C}, 373.41^{\circ} \mathrm{C}$ and $365^{\circ} \mathrm{C}$ for $\mathrm{C}, \mathrm{Cm}, \mathrm{Cmft}$, and $\mathrm{Cmftwt}$ models and experiment respectively. The temperature comparison shows that temperature from FEA numerical models are consistent with the experimental data and shows a similar temperature profile. From the temperature profile, it can be seen that there is a sharp increase in temperature as the time progresses when the pintool moves closer to the thermocouple. Afterwards the temperature reaches its peak value followed by a gradual temperature decrease as the pintool moves farther away from the thermocouple. From these results, it can be seen that the temperature profile of $\mathrm{C}$ - model and $\mathrm{Cm}$ - model show noticeable divergence compared to the experimental temperature profile at the start of welding. This can be explained by the fact that the friction coefficient used in these models is constant; i.e., not temperature dependent. This deviation in temperature profiles continues after the experimental temperature profile reaches its peak temperature. Results from the $\mathrm{Cmft}$ and Cmftwt models are closeer to the experimental result. This is more true for the Cmftwt model which produces the results that are closest to the experimental temperature profile throughout the entire weld process. This can be attributed to the fact that the Cmftwt model takes into account of the temperature dependent thermal properties of the workpiece in the model. This means that variation of physical parameters with temperature is important in the simulation of FSW.

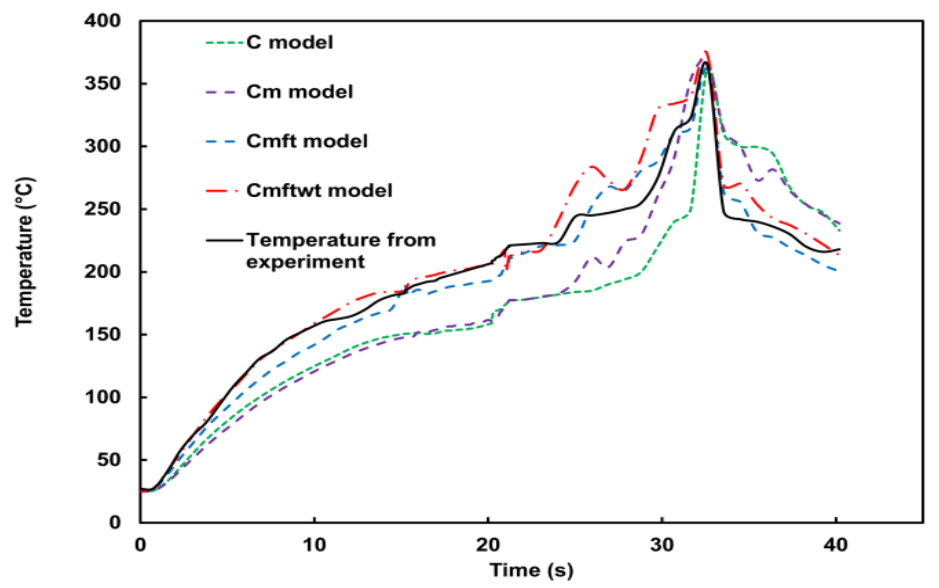

Fig. 12 Thermocouples and FEA temperature history comparison at location $3(\mathrm{x}=42.36 \mathrm{~mm}, \mathrm{z}=26 \mathrm{~mm})$ for different models

\section{Temperature validation along transverse direction}

Temperature along transverse direction at various distances from center of the weld for four different models have been obtained and compared with the experimental result as shown in Fig. 13. For C- model, we can see that temperatures from simulation are close to the experimental results in the vicinity of the center of the weld. However, deviation from the experimental temperature profile increases away from the center of the weld. Similar behavior is observed for the case of $\mathrm{Cm}$-model. albeit, the results are much closer compared to $\mathrm{C}$ - model temperature profile. This deviation can be explained by the fact that material properties of the workpiece are not temperature dependent and that the friction coefficient used in these contact models is constant rather than being temperature dependent. Temperature profiles obtained from Cmft- and Cmftwt- models show closer results compared to experimental temperature result. Again, Cmftwt- model results is the closest in comparison to experimental temperature profile. Comparison between the temperatures obtained from the FEA models and from experiment along transverse direction is also listed in Table 5

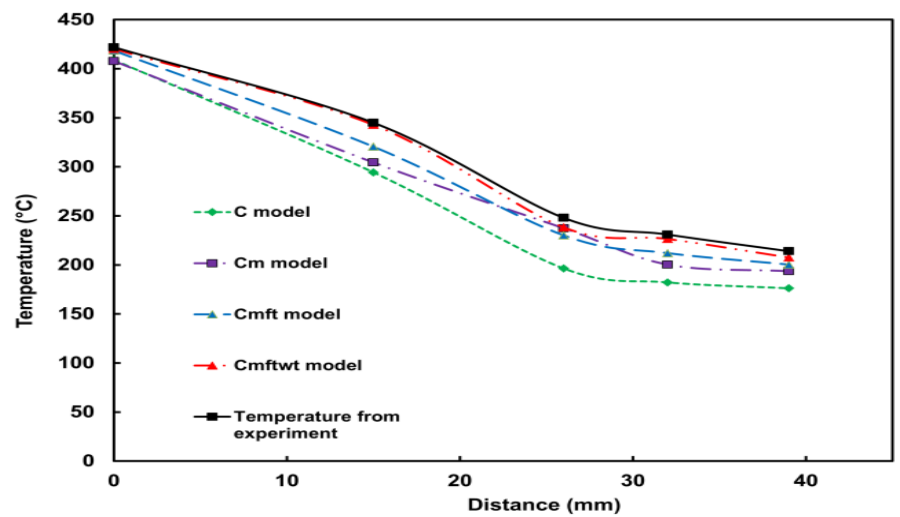

Fig. 13 Experimental and simulation temperature comparison along transverse direction for different models 
Table 5 Temperature comparison for different weld model along transverse direction

\begin{tabular}{|c|c|c|c|c|c|c|c|c|}
\hline Location & $\begin{array}{l}\text { Distance } \\
\text { from } \\
\text { center of } \\
\text { the weld } \\
(\mathrm{mm})\end{array}$ & $\begin{array}{l}\text { Temperature } \\
\text { from } \\
\text { experiment } \\
\left({ }^{\circ} \mathrm{C}\right)\end{array}$ & $\begin{array}{c}\text { Temp from } \\
\mathrm{C} \mathrm{model} \\
\left({ }^{\circ} \mathrm{C}\right)\end{array}$ & $\begin{array}{l}\text { Error } \\
\text { from C } \\
\text { model } \\
(\%)\end{array}$ & $\begin{array}{l}\text { Temperature } \\
\text { from } \mathrm{Cm} \\
\text { model } \\
\left({ }^{\circ} \mathrm{C}\right)\end{array}$ & $\begin{array}{c}\text { Error from } \\
\text { Cm model } \\
(\%)\end{array}$ & $\begin{array}{c}\text { Temperature from } \\
\text { Cmft } \\
\text { model } \\
\left({ }^{\circ} \mathrm{C}\right)\end{array}$ & $\begin{array}{c}\text { Error from } \mathrm{Cm} \\
\text { model } \\
(\%)\end{array}$ \\
\hline 1 & 0 & 422 & 400.8 & 5.0 & 407.9 & 3.3 & 418.5 & 3.3 \\
\hline 2 & 15 & 345 & 294.4 & 14.6 & 304.5 & 11.7 & 320.6 & 11.7 \\
\hline 3 & 26 & 248 & 196.4 & 20.8 & 237.4 & 4.3 & 230.2 & 4.3 \\
\hline 4 & 32 & 231 & 182.2 & 21.1 & 200.4 & 13.2 & 212.1 & 13.2 \\
\hline 5 & 39 & 214 & 176.2 & 21.4 & 193.6 & 9.5 & 200.4 & 9.5 \\
\hline
\end{tabular}

Table 5 continues......

\begin{tabular}{|c|c|c|c|c|c|c|}
\hline Location & $\begin{array}{l}\text { Distance from } \\
\text { center of the } \\
\text { weld }(\mathrm{mm})\end{array}$ & $\begin{array}{l}\text { Temperature from } \\
\text { experiment } \\
\left({ }^{\circ} \mathrm{C}\right)\end{array}$ & $\begin{array}{l}\text { Temperature from } \\
\text { Cmft model } \\
\left({ }^{\circ} \mathrm{C}\right)\end{array}$ & $\begin{array}{c}\text { Error from } \mathrm{Cmft} \\
\text { model } \\
(\%)\end{array}$ & $\begin{array}{c}\text { Temperature from } \\
\text { Cmftwt } \\
\text { model } \\
\left({ }^{\circ} \mathrm{C}\right)\end{array}$ & $\begin{array}{l}\text { Error from Cmftwt model } \\
(\%)\end{array}$ \\
\hline 1 & 0 & 422 & 416.5 & 1.3 & 420.3 & 0.4 \\
\hline 2 & 15 & 345 & 320.6 & 7.0 & 339.8 & 1.5 \\
\hline 3 & 26 & 248 & 230.2 & 7.1 & 238.3 & 3.9 \\
\hline 4 & 32 & 231 & 212.1 & 8.1 & 226.5 & 1.9 \\
\hline 5 & 39 & 214 & 200.4 & 6.3 & 207.6 & 2.99 \\
\hline
\end{tabular}

\section{V.COMPARISON OF MODELS FOR PINTOOL ROTATIONAL SPEED}

During FSW, heat is caused by two main sources- namely, heat generation from friction between pintool/workpiece and heat generation from plastic deformation of the plate. In the present study, both friction and plastic energy are analyzed using the developed models by analyzing energy histories during FSW.

In this section, effect of different rotational speeds is analyzed. Three rotational speeds were considered; low rotational speed: $200 \mathrm{rpm}$, moderate rotational speed: $350 \mathrm{rpm}$, and high rotational speed: $450 \mathrm{rpm}$. All three weld schedule have same weld speed of $1.27 \mathrm{~mm} / \mathrm{s}$ and same rate of plunge $0.4 \mathrm{~mm} / \mathrm{s}$. These rotational speeds were chosen from published experimental results [32]. Following are the experimental observation of the welding schedules that were analyzed in Table 6-

Table 6 Welding schedule for variation of rotational speed

\begin{tabular}{|c|c|c|c|c|}
\hline Welding Schedule & Rotational speed (rpm) & Welding speed $(\mathrm{mm} / \mathrm{s})$ & $\begin{array}{c}\text { Plunge rate } \\
(\mathrm{mm} / \mathrm{s})\end{array}$ & $\begin{array}{c}\text { Experimental } \\
\text { observation[32] }\end{array}$ \\
\hline Case-1 & 200 & 1.27 & 0.4 & Defect weld \\
\hline Case-2 & 350 & 1.27 & 0.4 & Defect free weld \\
\hline Case-3 & 450 & 1.27 & 0.4 & Defect weld \\
\hline
\end{tabular}

\section{Case 1: low rotational speed: $200 \mathrm{rpm}$}

\section{V.1.1 Modeling Effect on Frictional Energy}

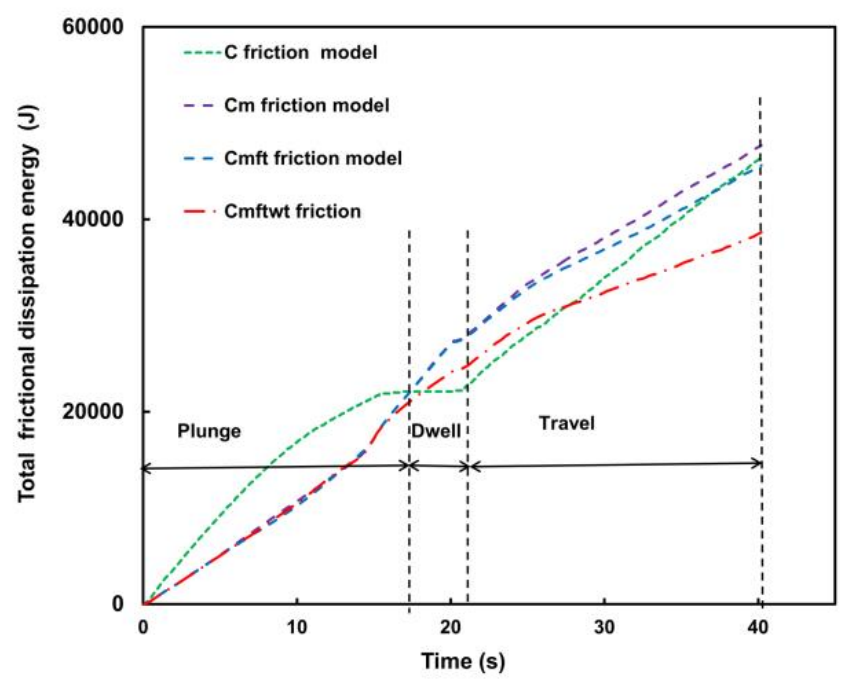

Fig. 14 Friction energy comparison for different models $(N=200 \mathrm{rpm})$ 
Fig. 14 shows a comparison of the friction energy from different models for the case of low rotational speed of $200 \mathrm{rpm}$. From the figure, it can be seen that the friction energy obtained using the $\mathrm{C}$ - model during plunge stage is higher than that obtained using the $\mathrm{Cm}, \mathrm{Cmft}$, and Cmftwt- models. This can be explained by the fact that, the shear stress is limited to $\frac{\sigma_{y}}{\sqrt{3}}$ in the modified coulomb model friction model instead of being a function of the friction coefficient and the solution-dependent contact pressure calculated in the Coulomb friction model. During the travel stage, the $\mathrm{Cm}$-model generates the highest amount of energy compared to other models. The friction coefficient is fixed $(\mu=0.3)$ in the $\mathrm{Cm}$ - model, whereas it is temperature dependent in the $\mathrm{Cmft}$ and Cmftwt models, resulting in the generation of higher amounts of friction energy. It can be seen that the $\mathrm{C}$, $\mathrm{Cm}$, and $\mathrm{Cmft}$ models behave almost linearly during the travel stage. Furthermore, the Cmftwt model shows less friction energy among the three models that use the modified Coulomb friction model $(\mathrm{Cm}, \mathrm{Cmft}$ and $\mathrm{Cmftwt}$ models). This is attributed to the fact that the Cmftwt model material properties are temperature dependent; i.e., as the temperature increases, the modulus of elasticity decreases.

\section{V.1.2 Modeling Effect on Plastic dissipation Energy for 200 rpm}

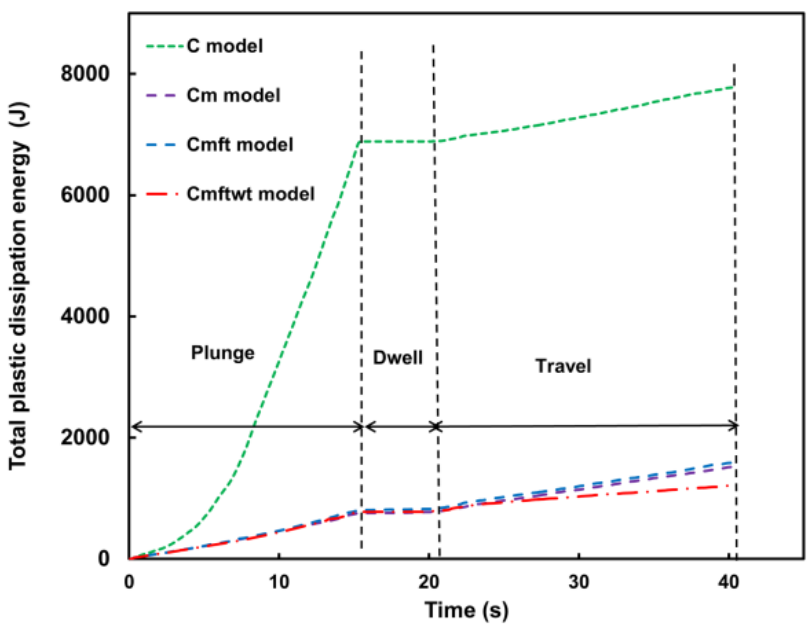

Fig. 15 Plastic energy comparison for different models $(N=200 \mathrm{rpm})$

Fig. 15 shows a comparison of plastic energy obtained from different models at $200 \mathrm{rpm}$. From the fig, it can be seen that Cmodel shows high amounts of plastic energy during all three stages of FSW (plunge, dwell, and travel stage) in comparison to other models. As stated earlier, this can be explained by the fact that in Coulomb model (C-model) friction stress is not limited by a maximum value as it is the other models adopting the modified Coulumb Friction Law. This allows the material underneath the pintool to be in a sticking condition until it reaches critical value $\left(\tau_{\text {crit }}=\mu P\right)$ and then starts sliding. Conversely, the stick/slide condition in the modified Coulomb models is governed by the shear stress limit taken as $\frac{\sigma_{y}}{\sqrt{3}}$, which is lower value than $\mu P$. Therefore, the Coulomb model exhibits higher plastic dissipation energy compare to modified Coulomb models. However, this high amount of plastic energy exhibited by C- model is unrealistic based on experimental observation. Experimental work done by our research group has shown that low pintool rotational speeds causes insufficient plastic deformation contrary to what the C- model predicts, which leads to defects (wormholes, internal cavities, trenching surface cavities) [32].

\section{V.1.3 Modeling Effect on Maximum Equivalent Plastic Strain}

(a)

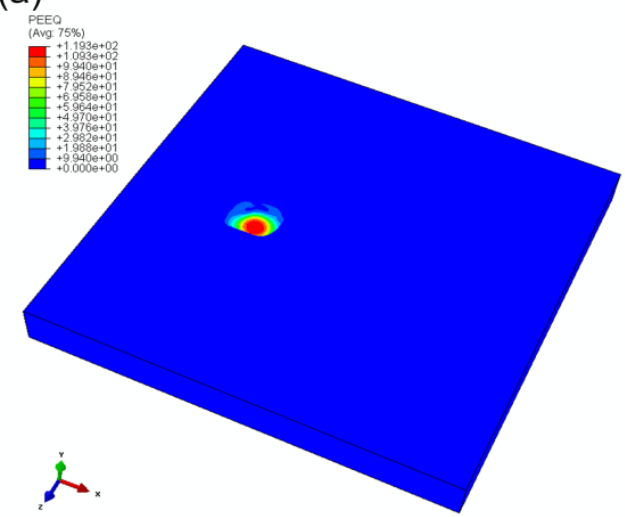

(b)

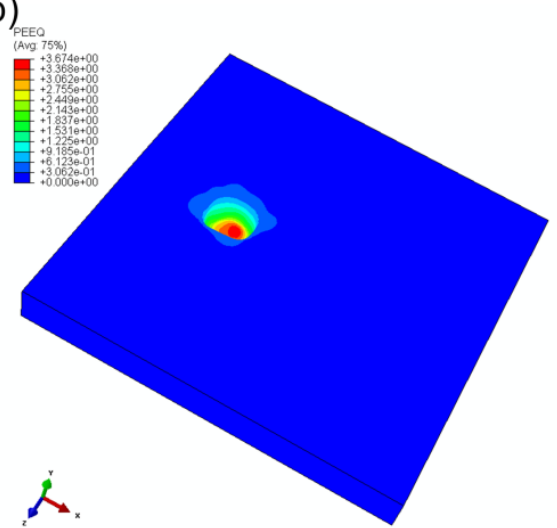


(c)

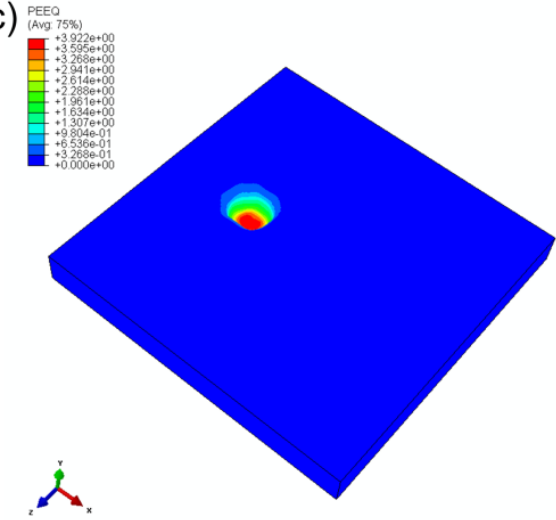

(d)

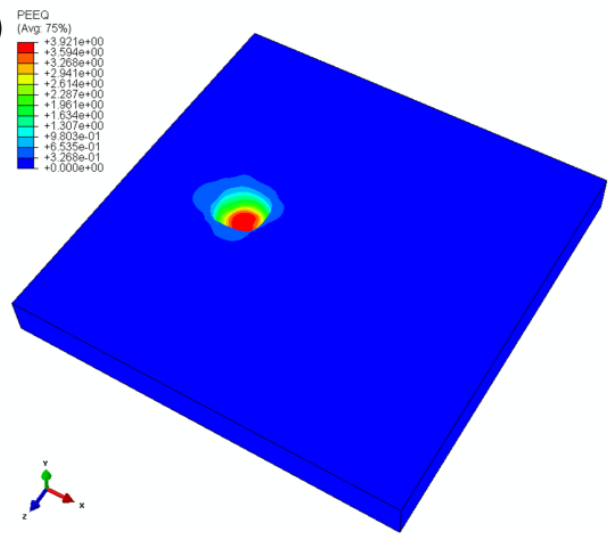

Fig. 16 Maximum equivalent plastic strain for different model at $200 \mathrm{rpm}$ (a) $\mathrm{C}$ model (b) $\mathrm{Cm}$ model (c) Cmft model (d) Cmftwt model

Fig. 16 (a)-(d) shows plots of the equivalent plastic strain for the $\mathrm{C}, \mathrm{Cm}, \mathrm{Cmft}$, and Cmftwt models respectively at low rotational speed of $200 \mathrm{rpm}$. From the figures, it can be seen that the C-model predicts a maximum equivalent plastic strain of 118 . Whereas, for the other three models $(\mathrm{Cm}, \mathrm{Cmft}$, and $\mathrm{Cmftwt})$, the maximum equivalent plastic strain is 3.7, 4.0, 3.9 respectively. In other words, the $\mathrm{C}$ - model exhibits much higher amount of maximum equivalent plastic strain compared to $\mathrm{Cm}$, $\mathrm{Cmft}$, and $\mathrm{Cmftwt}$ models at lower rotational speed. As stated earlier, the stick to slide criterion in the Coulomb model has a higher limiting value compared to modified Coulomb friction models. This allows Coulomb model to exhibit higher maximum equivalent plastic strain. Also, as mentioned in Section V.1.2 this high amount of maximum equivalent plastic strain shown by C-model is not corroborated by the experimental observations made by our research group [32].

\section{V.1.4 Modeling Effect on Energy ratio variation with time}

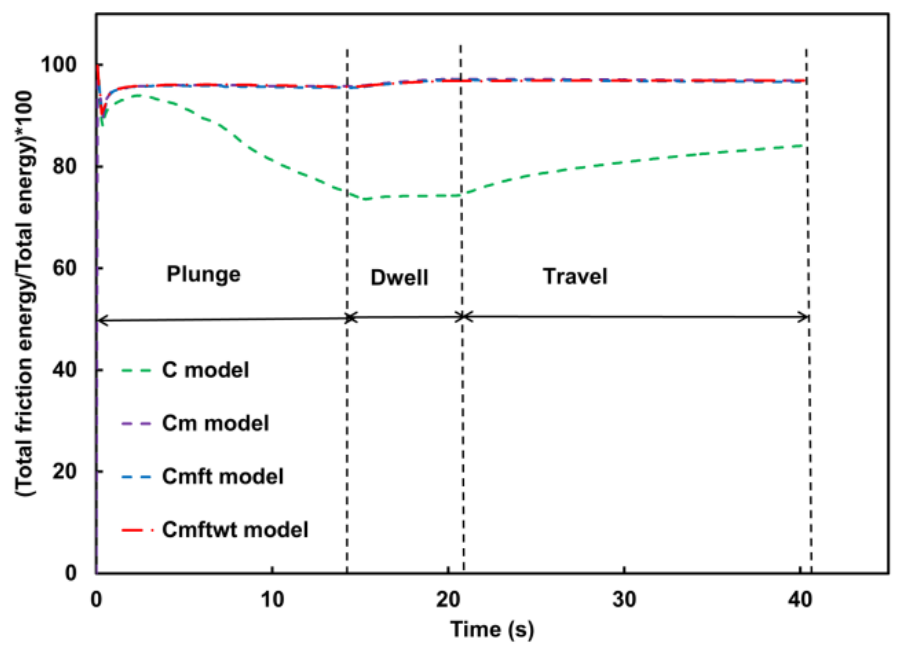

Fig. 17 Variation of ( $\left.\frac{\text { Friction energy }}{\text { Total energy }}\right)$ for different model $(N=200 \mathrm{rpm})$

Fig. 17 shows the friction energy to total energy ratio, $\frac{\text { Friction energy }}{\text { Total energy }}$, obtained using different models for rotational speed of 200 $\mathrm{rpm}$. For C- model, it can be seen that during plunge stage there is a decrease of ( $\left.\frac{\text { Friction energy }}{\text { Total energy }}\right)$ as the time progress. This suggests that, during the plunge stage for $\mathrm{C}$ - model, the contribution of friction energy ratio is low compare to $\mathrm{C}, \mathrm{Cm}, \mathrm{Cmft}$, and $\mathrm{Cmftwt}$ models. However, during dwell stage we can see that $\left(\frac{\text { Friction energy }}{\text { Total energy }}\right)$ is almost constant for all the models. Finally, the C- model shows almost linear increase of $\left(\frac{\text { Friction energy }}{\text { Total energy }}\right)$ with respect to time during the travel stage. Furthermore, Fig. 17 also shows that the $\left(\frac{\text { Friction energy }}{\text { Total energy }}\right)$ is almost constant during all stages of FSW for the $\mathrm{Cm}, \mathrm{Cmft}$, and Cmftwt models. 


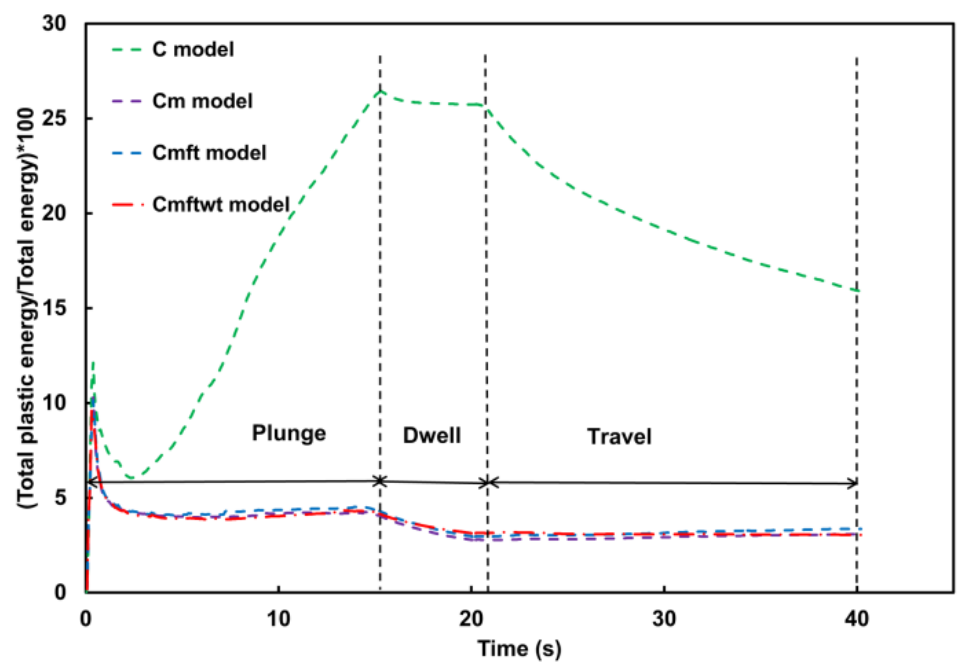

Fig. 18 Variation of $\left(\frac{\text { Plastic energy }}{\text { Total energy }}\right)$ for different model $(N=200 \mathrm{rpm})$

Fig. 18 shows aplot of the $\left(\frac{\text { Plastic energy }}{\text { Total energy }}\right)$ ratio for all models at the same rotational speed $(200 \mathrm{rpm})$. From the plot in Fig. 18 , it is clear that the $\mathrm{C}$ - model predicts a sharp increase in the plastic energy ratio, which indicates severe plastic deformation. During the dwell stage, the ( $\frac{\text { Plastic energy }}{\text { Total energy }}$ ) ratio decreases slightly. Finally, during the travel stage, there is a sharp decrease in ( $\left.\frac{\text { Plastic energy }}{\text { Total energy }}\right)$ ratio. Conversely, no sharp rise of energy ratio is observed during the plunge, dwell or travel step for Cm, Cmft, and Cmftwt models. In reality, insufficient plastic deformation is observed at this low rotation speed of $200 \mathrm{rpm}$, based on the experimental work done by our group [32]. Also from experiments, our research group has shown that this inadequate plastic deformation promotes the development of defects such as internal cavities or surface cavities. Therefore, Coulomb model (C model) is not capable of capturing plastic deformation accurately for weld schedules with low rotational speeds. Earlier research by Zhang et al. [30] reported they did not observe distinguishable difference between Coulomb and modified Coulomb models at low rotation speed.

\section{Case 2: Intermediate rotational speed: $350 \mathrm{rpm}$}

\section{V.1.5 Modeling Effect on Frictional Energy}

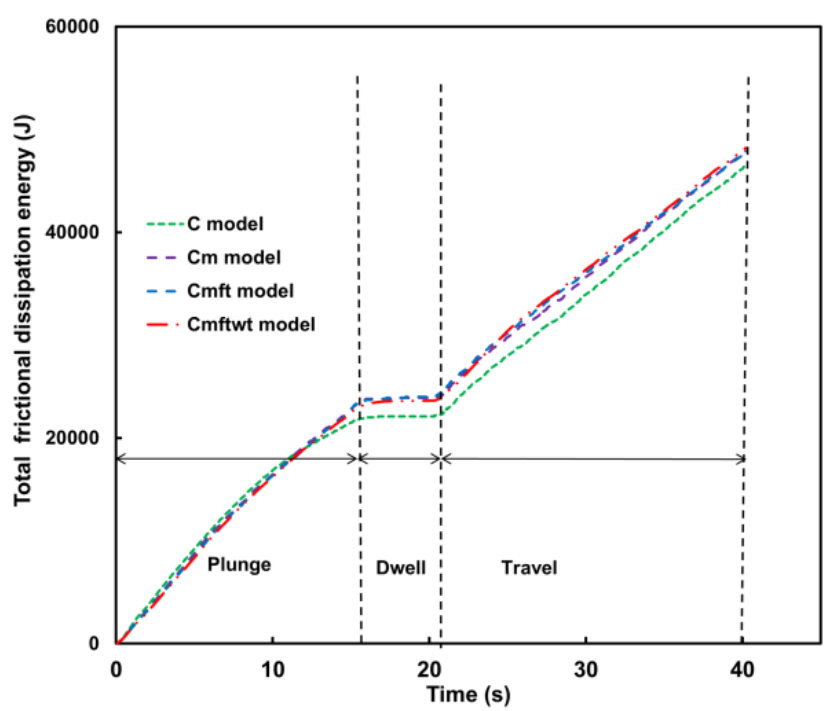

Fig. 19 Frictional dissipation energy variation for different models $(N=350 \mathrm{rpm})$ 
Fig. 19 shows comparison of friction energy generated during the welding process according to the different models at a rotational speed of $350 \mathrm{rpm}$. During all stages of FSW, all models $(\mathrm{C}, \mathrm{Cm}, \mathrm{Cmft}$, and Cmftwt) produce almost similar amount of frictional dissipation energy. Therefore, it can be said that Coulomb and modified Coulomb model exhibit identical frictional energy at intermediate rotational speed.

\section{V.1.6 Modeling Effect on Plastic dissipation Energy}

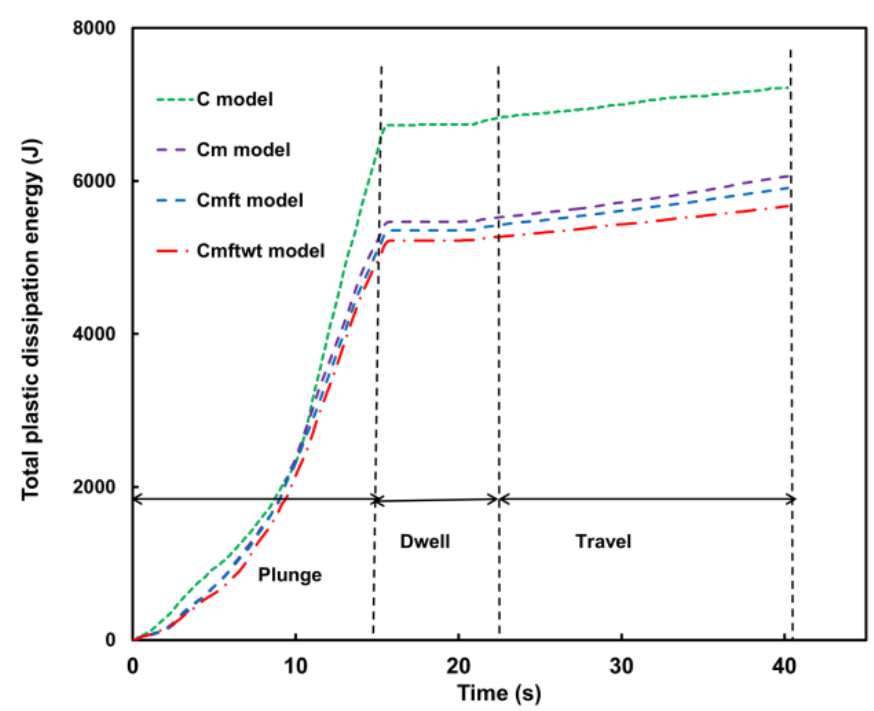

Fig. 20 Plastic energy dissipation energy variation for $(N=350 \mathrm{rpm})$

Fig. 20 shows the amounts of plastic energy predicted by different models for the $350 \mathrm{rpm}$ rotational speed. The comparison of all four models shows that Coulomb model (C model) produces higher energy in all steps of FSW compared to the modified Coulomb models (Cm, Cmft, and Cmftwt). As mentioned earlier in Section V.1.2, in Coulomb model (C- model) friction stress is not limited to a maximum value, which allows the plastic dissipation energy to increase before sliding when it reaches critical value $\left(\tau_{\text {crit }}=\mu P\right)$. On the other hand, in modified Coulomb model stick/slide condition is defined using $\frac{\sigma_{y}}{\sqrt{3}}$, which has a lower value compared to $\mu P$, therefore plastic dissipation energy is low compared to Coulomb model. Consequently, the Coulomb model exhibits higher plastic dissipation energy than exhibited by the modified Coulomb models.

\section{V.1.7 Modeling Effect on Maximum Equivalent plastic strain}

(a)

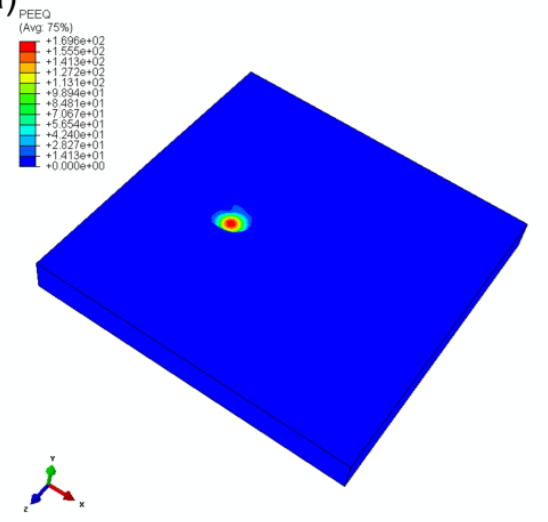

(b)

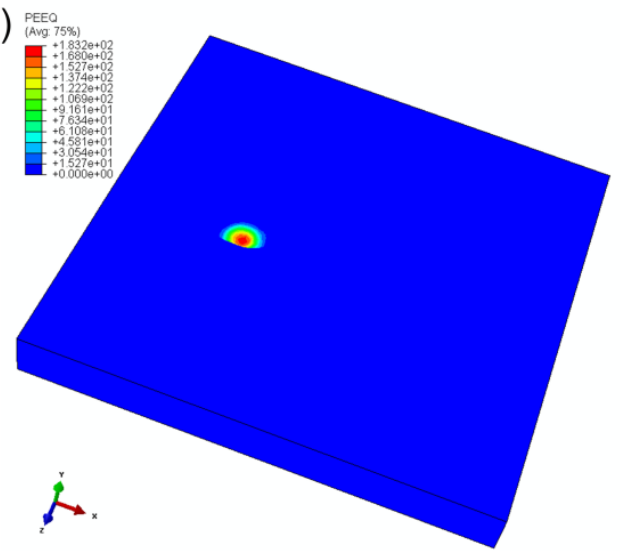


(c)

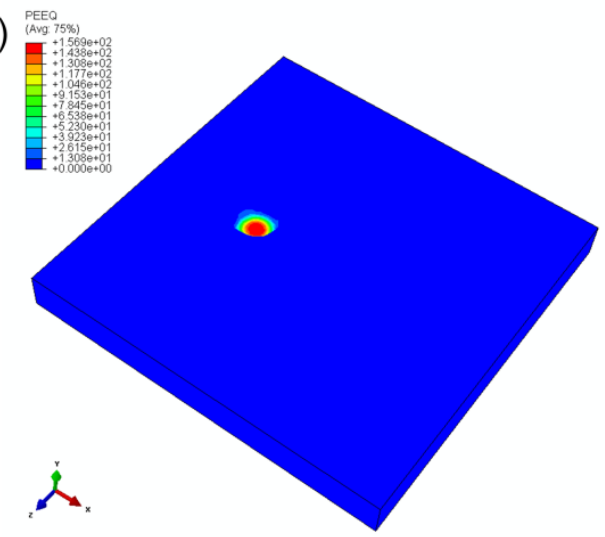

(d)

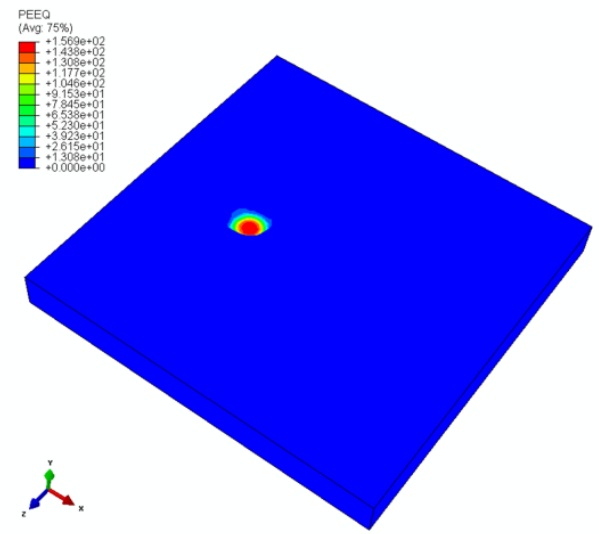

Fig. 21 Maximum equivalent plastic strain for different model at $350 \mathrm{rpm}$ (a) $\mathrm{C}$ model (b) $\mathrm{Cm}$ model (c) Cmft model (d) Cmftwt model

Fig. 21(a)-(d) represent equivalent plastic strain result for $\mathrm{C}, \mathrm{Cm}, \mathrm{Cmft}$, and Cmftwt model. For $\mathrm{C}, \mathrm{Cm}, \mathrm{Cmft}$, and $\mathrm{Cmftwt}$ models maximum equivalent plastic strain is $169,183,156$, and 156 respectively. From the above discussion it can be seen that at this intermediate weld rotational speed $(N=350 \mathrm{rpm})$, the classical Coulomb model $(\mathrm{C}$ - model) and the modified Coulomb friction models $(\mathrm{Cm}, \mathrm{Cmft}$, and $\mathrm{Cmftwt})$ produced maximum equivalent plastic strain within a narrow range with slight variations.

\section{V.1.8 Modeling Effect on Energy ratio variation with time}

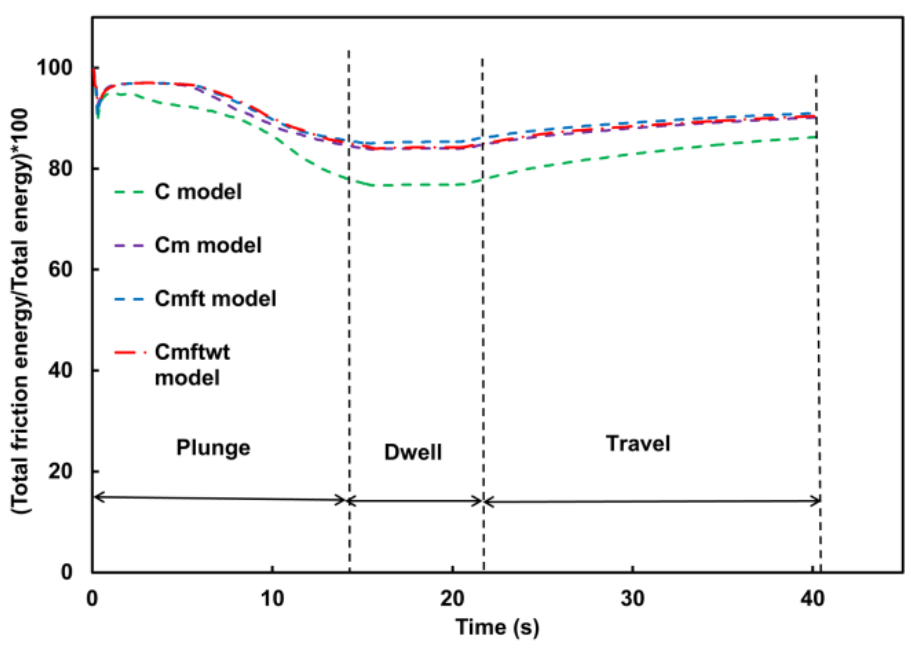

Fig. 22 Variation of ( $\left.\frac{\text { Friction energy }}{\text { Total energy }}\right)$ for different models $(N=350 \mathrm{rpm})$

Fig. 22 shows a comparison of the ( $\left.\frac{\text { Friction energy }}{\text { Total energy }}\right)$ ratio obtained using the different models at $N=350 \mathrm{rpm}$. All models show similar friction energy ratio as time progresses. Among the models, C- model shows lower amount of friction energy ratio compared to $\mathrm{Cm}, \mathrm{Cmft}$, and Cmftwt models. It can also be seen that the $\mathrm{Cm}, \mathrm{Cmft}$, and Cmftwt models produce very similar friction energy ratios during all stages of FSW. Comparing Fig. 22 and Fig. 16, it can be said that the difference between the predicted $\left(\frac{\text { Friction energy }}{\text { Total energy }}\right)$ ratio from the classical Coulomb model $(\mathrm{C}$ - model $)$ and modified Coulomb model $(\mathrm{Cm}, \mathrm{Cmft}$, and Cmftwt models $)$ is less for the moderate rotational speed $(N=350)$ than it is for the low rotational speed $(N=200 \mathrm{rpm})$. 


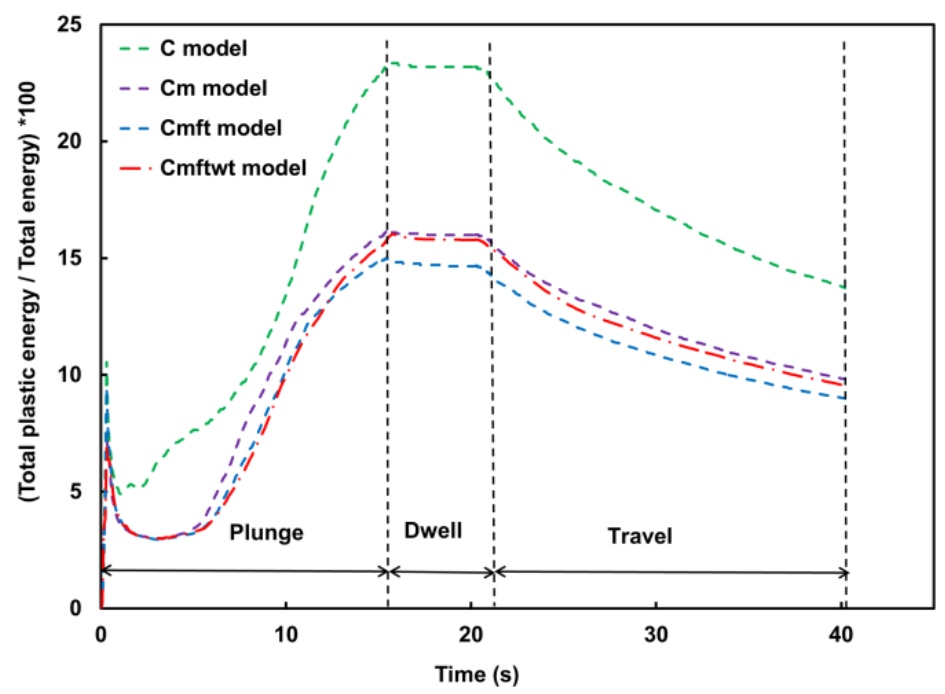

Fig. 23 Variation of $\left(\frac{\text { Plastic energy }}{\text { Total energy }}\right)$ for different models $(N=350 \mathrm{rpm})$

Fig. 23 shows the ( $\left.\frac{\text { Plastic energy }}{\text { Total energy }}\right)$ ratio obtained from the different model at $N=350 \mathrm{rpm}$. Among the models, Coulomb model (Cmodel) shows higher amount of plastic energy ratio compare to modified Coulomb $(\mathrm{Cm}, \mathrm{Cmft}$, and Cmftwt) models. As stated earlier, the Coulomb model allows more plastic energy dissipation before sliding as sticking/sliding limit value is higher compare to modified Coulomb model. For all models, it can be seen that during the plunge step there is sharp increase of plastic energy ratio as the time progresses. This can be clarified by the way that a large amount of materials are pierced by the summit of the pintool(pin nib) at plunge step, which causes high plastic deformation underneath the pintool. However, during the dwell stage plastic energy ratio is constant for all models. Toward the end of dwell step, plastic deformation becomes linear during travel step as large deformations due to the compounded effect of plunging and stirring are drastically reduced. All models show linear decrease of energy ratio with respect to time during the travel stage.

\section{Case 3: High rotating speed: $450 \mathrm{rpm}$}

\section{V.1.9 Modeling Effect on Frictional Energy}

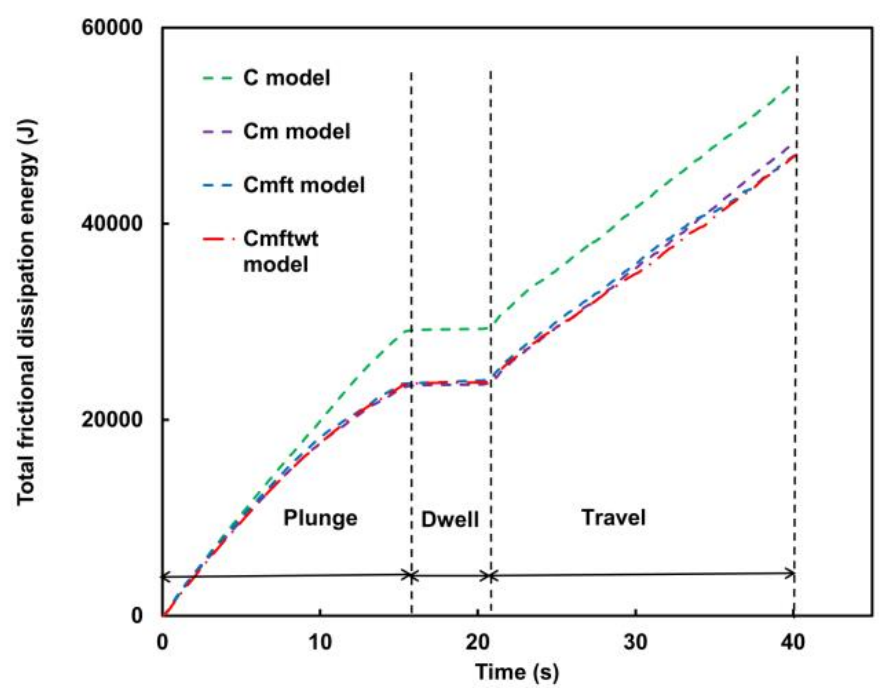

Fig. 24 Frictional dissipation energy variation for $450 \mathrm{rpm}$ for different model 
Fig. 24 shows comparison of friction energy of different models at high rotation speed of 450 rpm. From Fig. 24 it can be seen that Coulomb model (C-model) produces distinguishable higher amount of friction energy compare to modified Coulomb model (Cm, Cmft and Cmftwt models) during all steps of FSW. This higher amount of friction energy of C- is contributed by limit applied in friction stress in Coulomb model as described in Section V.1.5. Other three models developed using modified Coulomb model (Cm, Cmft, Cmftwt model) show identical friction energy throughout all three stages of FSW.

\section{V.1.10 Modeling Effect on Plastic Dissipation Energy}

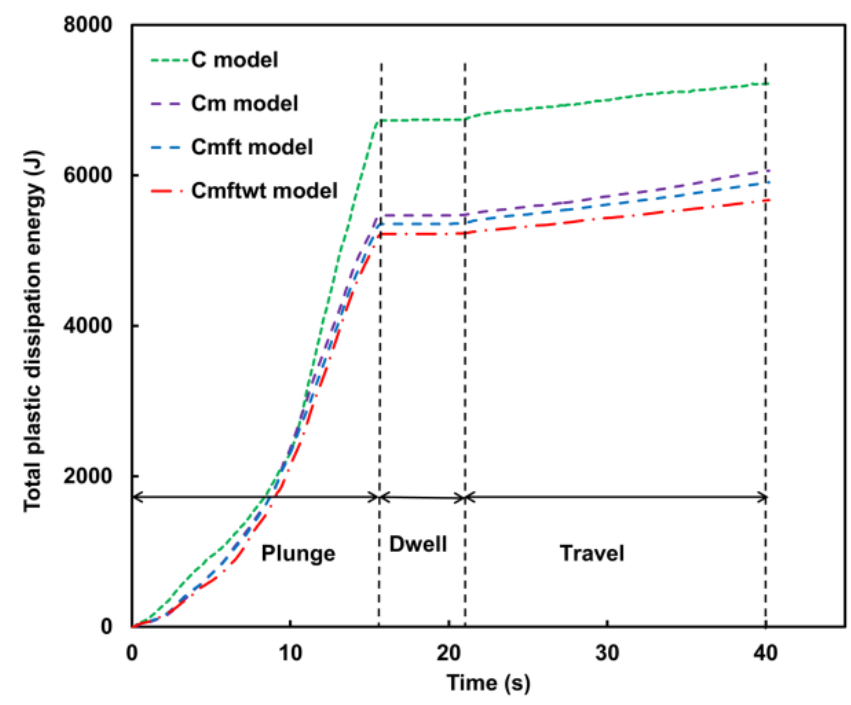

Fig. 25 Plastic dissipation energy variation for different model $(N=450 \mathrm{rpm})$

The effect of plastic energy is compared for $450 \mathrm{rpm}$ for plunge, dwell, and travel stages in Fig. 25. Comparison of the results from all models shows that classical Coulomb model (C- model) produces higher plastic dissipation energy in plunge, dwell, and travel stages compared to modified Coulomb models $(\mathrm{Cm}, \mathrm{Cmft}$, and $\mathrm{Cmftwt})$ as a result of the difference in the limiting stress value that governs the stick/slide condition as discussed earlier.

\section{V.1.11 Modeling Effect on Maximum Equivalent plastic strain}

(a)

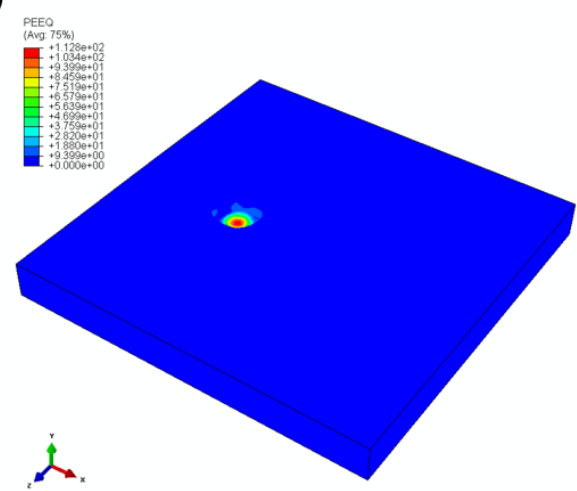

(b)

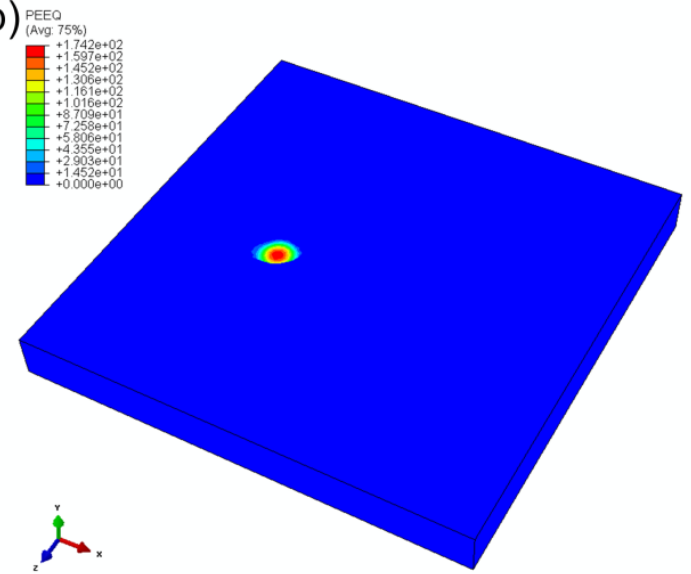


(c)

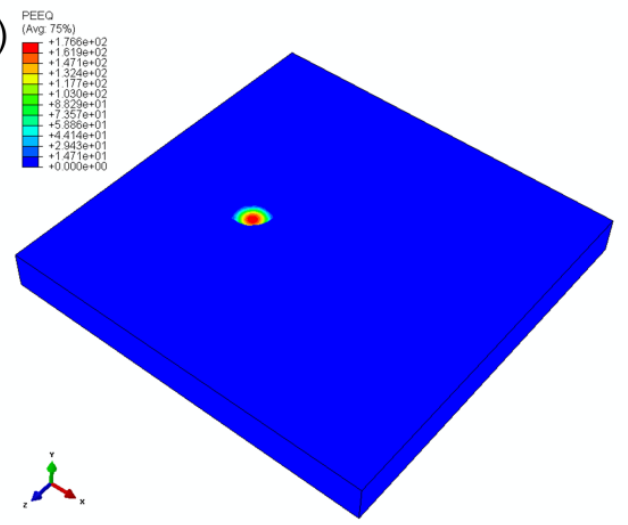

(d)

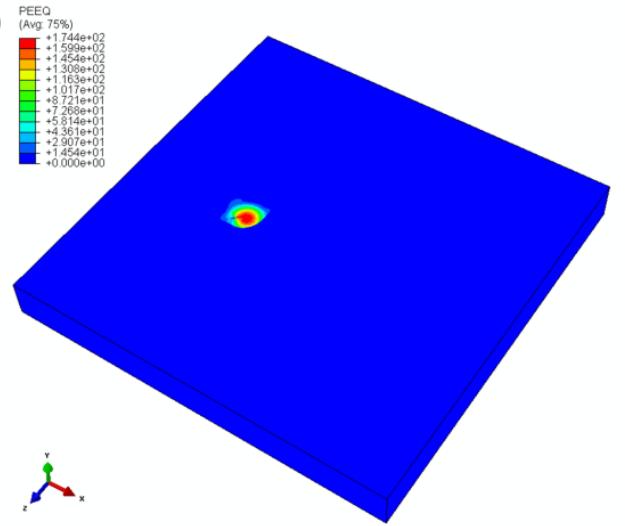

Fig. 26 Maximum equivalent plastic strain for different model at $450 \mathrm{rpm}$ (a) $\mathrm{C}$ model (b) $\mathrm{Cm}$ model (c) Cmft model (d) Cmftwt model

Fig. 26 (a)-(d) show plots of the maximum equivalent plastic strain energy at $450 \mathrm{rpm}$ rotational speed. The maximum equivalent plastic strain was found to be 112.8, 174.2, 176.6 and 174.4 for the $\mathrm{C}, \mathrm{Cm}$, Cmft, Cmftwt models, respectively. From the result, it can be seen that at high rotational speed $(N=450 \mathrm{rpm})$, classical Coulomb model $(\mathrm{C}$ - model) predicted lower maximum equivalent plastic strain compared to modified Coulomb friction model $(\mathrm{Cm}, \mathrm{Cmft}, \mathrm{Cmftwt}$ models) .

\section{V.1.12 Modeling Effect on Energy ratio variation with time}

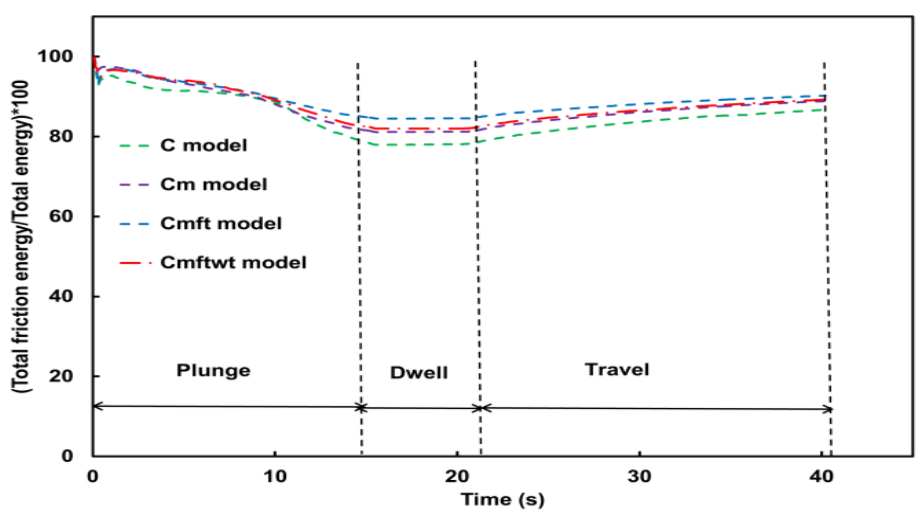

Fig. 27 Variation of ( $\left.\frac{\text { Friction energy }}{\text { Total energy }}\right)$ for different model at $450 \mathrm{rpm}$

Fig. 27 shows a comparison of the ( $\left.\frac{\text { Friction energy }}{\text { Total energy }}\right)$ ratio for all models at high pintool rotational speed of $450 \mathrm{rpm}$. Unlike the low $(N=200 \mathrm{rpm})$ and moderate $(N=350 \mathrm{rpm})$ rotational speed, all models show very similarly ( $\left.\frac{\text { Friction energy }}{\text { Total energy }}\right)$ ratio. Therefore, it can be seen that Coulomb model (C- model) exhibits comparable friction energy ratio compare to modified Coulomb contact model ( $\mathrm{Cm}, \mathrm{Cmft}$, and $\mathrm{Cmftwt}$ models) at high rotation speed of the pintool.

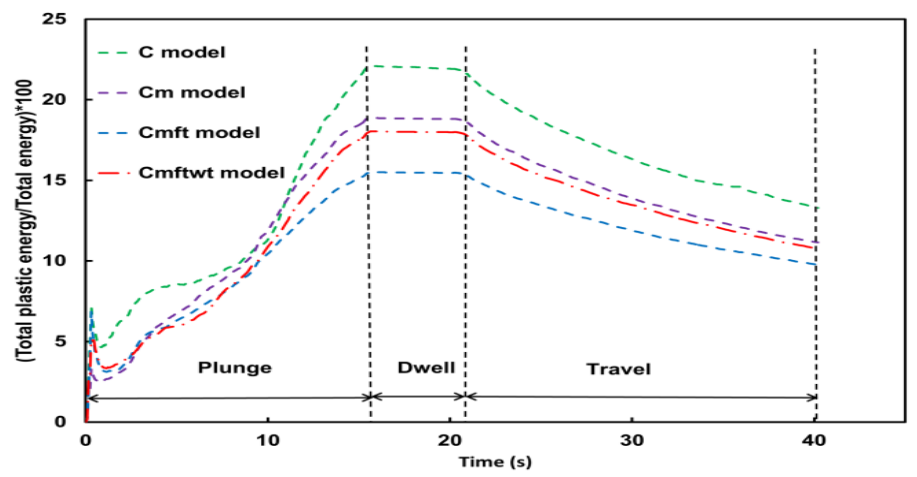

Fig. 28 Variation of ( $\left.\frac{\text { Plastic energy }}{\text { Total energy }}\right)$ for different model at $450 \mathrm{rpm}$ 
In Fig. 28, it can be seen that the $\frac{\text { Plastic energy }}{\text { Total energy }}$ ratio increases sharply during the plunge step for all models. As mentioned earlier in Section V.1.8 this indicates that there is huge amount of material deformed underneath by the pin nib (summit of the pintool) during plunge stage, which causes high plastic deformation underneath the pintool. During the dwell stage, the ( $\left.\frac{\text { Plastic energy }}{\text { Total energy }}\right)$ energy ratio remains almost constant. At the beginning of the travel stage, there is a sharp decrease in the ( $\left.\frac{\text { Plastic energy }}{\text { Total energy }}\right)$ ratio for all four models. During travel stage all models show linear decrease of energy ratio with respect to time. As mentioned earlier in Section V.1.8, during the end of dwell stage, plastic deformation becomes linear during travel stage as large deformations due to the compounded effect of plunging and stirring no longer occur. Among the models, $\mathrm{C}$ - model shows higher amount of plastic energy ratio compare to $\mathrm{Cm}, \mathrm{Cmft}$, and $\mathrm{Cmftwt}$ model. As mentioned earlier, the change of sticking to sliding condition has a higher limiting value of critical stress in Coulomb model $(\mathrm{C}$ - model), compare to modified Coulomb model $(\mathrm{Cm}, \mathrm{Cmft}$, and Cmftwt model) which causes generation of high plastic dissipation energy in Coulomb model compare to modified Coulomb model.

\section{VI.CONCLUSIONS}

Four different models have been developed in this study to simulate the FSW process, and use the results to the study the effect of pintool's rotational speed on the heat energy generation in the workpiece. The four models are: (i) C- model: Coulomb contact model with constant friction coefficient, (ii) $\mathrm{Cm}$ - model: modified Coulomb contact model with constant friction coefficient, (iii) Cmft- model: Modified Coulomb contact model with temperature dependent friction coefficient, and (iv) Cmftwt-model: Workpiece material properties temperature dependent along with modified Coulomb contact model with temperature dependent friction coefficient. The result obtained from this research can be summarized as follows:

1. The temperature field obtained from the FE simulations are in good agreement with the temperature field obtained experimentally through FSW of Al-AA 2219 alloy. Among the four developed models, the Cmftwt model produces the closest temperature profile to the experimentally obtained profile.

2. At low rotational speed, the Coulomb model generates higher friction energy compared to the modified Coulomb models during plunge stage. At moderate rotational speed, no such difference is observed among the Coulomb and modified Coulomb model. At high rotational speed, the Coulomb model exhibits higher friction energy compared to the modified Coulomb models during all steps of FSW. This is attributed to the fact that the friction stress is limited to $\frac{\sigma_{y}}{\sqrt{3}}$ in the modified Coulomb model as opposed to being a function of the friction coefficient and the solution-dependent contact pressure calculated in the Coulomb friction model with no upper limit.

3. At low, moderate, and high rotational speeds, the Coulomb model shows high plastic dissipation energy compare to modified Coulomb models. The fact that the friction stress has not upper limit in the Coulomb model allows the plastic dissipation energy to increase before sliding when it reaches critical value $\left(\tau_{c r i t}=\mu P\right)$. Conversely, the stick/slide condition in modified Coulomb models is defined using $\frac{\sigma_{y}}{\sqrt{3}}$, which is typically lower compared to $\mu P$. Therefore, the plastic dissipation energy is lower than that obtained using the Coulomb model. At low rotational speed, the Coulomb model exhibits unrealistic high plastic deformation; which was not observed experimentally. Low rotational speeds cause insufficient temperature field due to the generation of low frictional and plastic dissipation energies, which eventually causes defects such as: wormholes, surface cavities, and incomplete penetration. As a result, Coulomb model cannot accurately represent contact condition at low rotation speed.

4. At low rotation speed, Coulomb model shows extremely high maximum equivalent plastic strain compared to other models. This high maximum equivalent plastic strain of Coulomb model is not corroborated experimentally based on work done by our research group, which has shown that at low rotational speed there is insufficient plastic deformation which leads to defects such as wormholes or internal cavities and trenching or surface cavities. Therefore, the Coulomb model cannot simulate contact between pintool and workpiece at low rotational speed.

\section{ACKNOWLEDGMENT}

The authors appreciatively perceive the financial help got from the Louisiana Economic Development Assistantship (EDA) program and the partial support received from NASA-SLS Grant NNM13AA02G. The authors want to offer their earnest thanks to the National Center for Advanced Manufacturing, NASA's Michoud Assembly Facility in New Orleans, Louisiana and NASA's Marshall Space Flight Center for allowing the authors to use their experimental facility and their contribution to the experimental program of this research. Any opinions, findings, and conclusions or recommendations expressed in this material are those of the author(s) and do not necessarily reflect the views of the sponsors of this research.

REFERENCE

[1] J. C. N. W.M. Thomas, M.G. Murch, P.Templesmith, C.J. Dawes, International patent application no. PCT/GB92102203 and Great Britain patent application no. 9125978.8 (1991)

[2] M. Pirizadeh, T. Azdast, S. Rash Ahmadi, S. Mamaghani Shishavan, and A. Bagheri, Materials \& Design (1980-2015) 54, 342 (2014),

[3] Y. J. Chao, X. Qi, and W. Tang, J. Manuf. Sci. Eng.-Trans. ASME 125, 138 (2003).

[4] C. Chen and R. Kovacevic, Proc. Inst. Mech. Eng. Part C-J. Eng. Mech. Eng. Sci. 218, 509 (2004).

[5] Z. Zhang and H. W. Zhang, Int. J. Adv. Manuf. Technol. 37, 279 (2008).

[6] X. X. Zhang, B. L. Xiao, and Z. Y. Ma, Metall. Mater. Trans. A-Phys. Metall. Mater. Sci. 42A, 3218 (2011). 
[7] G. Buffa, J. Hua, R. Shivpuri, and L. Fratini, Mater. Sci. Eng. A-Struct. Mater. Prop. Microstruct. Process. 419, 389 (2006).

[8] P. Ulysse, Int. J. Mach. Tools Manuf. 42, 1549 (2002)

[9] P. A. Colegrove and H. R. Shercliff, Sci. Technol. Weld. Join. 11, 429 (2006).

[10] C. Hamilton, A. Sommers, and S. Dymek, International Journal of Machine Tools and Manufacture 49, 230 (2009).

[11] C. Hamilton, S. Dymek, and A. Sommers, International Journal of Machine Tools and Manufacture 48, 1120 (2008).

[12] H. N. B. Schmidt, T. L. Dickerson, and J. H. Hattel, Acta Materialia 54, 1199 (2006).

[13] A. Gerlich, M. Yamamoto, and T. H. North, Metall. Mater. Trans. A-Phys. Metall. Mater. Sci. 38A, 1291 (2007).

[14] P. Heurtier, M. J. Jones, C. Desrayaud, J. H. Driver, F. Montheillet, and D. Allehaux, Journal of Materials Processing Technology 171, 348 (2006).

[15] H. Schmidt, J. Hattel, and J. Wert, Model. Simul. Mater. Sci. Eng. 12, 143 (2004).

[16] R. Nandan, G. G. Roy, T. J. Lienert, and T. Debroy, Acta Materialia 55, 883 (2007).

[17] H. Su, C. S. Wu, A. Pittner, and M. Rethmeier, Energy 77, 720 (2014).

[18] Z. Zhang and H. W. Zhang, Sci. Technol. Weld. Join. 12, 226 (2007).

[19] H. Schmidt and J. Hattel, Model. Simul. Mater. Sci. Eng. 13, 77 (2005).

[20] M. Abbasi, B. Bagheri, and R. Keivani, J. Mech. Sci. Technol. 29, 861 (2015).

[21] M. Assidi, L. Fourment, S. Guerdoux, and T. Nelson, Int. J. Mach. Tools Manuf. 50, 143 (2010).

[22] H. W. Zhang, Z. Zhang, and J. T. Chen, Journal of Materials Processing Technology 183, 62 (2007).

[23] V. Soundararajan, S. Zekovic, and R. Kovacevic, International Journal of Machine Tools and Manufacture 45, 1577 (2005).

[24] S. B. Aziz, M. W. Dewan, D. J. Huggett, M. A. Wahab, A. M. Okeil, and T. W. Liao, Acta Metallurgica Sinica-English Letters 29, 869 (2016).

[25] S. B. Aziz, M. W. Dewan, D. J. Huggett, M. A. Wahab, A. M. Okeil, and T. W. Liao, Acta Metallurgica Sinica(English letters) (2017).

[26] L. Shi, Wu, C.S. \& Liu, H.J., Int J Adv Manuf Technol 74, 319 (2014).

[27] A. A. Waheed, L. O. Jayesimi, M. A. Ismaila, and U. O. Dairo, Journal of Applied and Computational Mechanics 3, 37 (2017).

[28] S. Zhang, G. Chen, Q. Liu, H. Li, G. Zhang, G. Wang, and Q. Shi, Journal of Manufacturing Processes 33, 245 (2018).

[29] Z. Sun, C. S. Wu, and S. Kumar, Journal of Manufacturing Processes 31, 801 (2018).

[30] Z. Zhang, J. Mater. Sci. 43, 5867 (2008).

[31] R. S. Mishra and Z. Y. Ma, Materials Science and Engineering: R: Reports 50, 1 (2005).

[32] M. W. Dewan, D. J. Huggett, T. W. Liao, M. A. Wahab, and A. M. Okeil, Materials \& Design 92, 288 (2016).

[33] G. R. C. Johnson, W.H., in Proceedings of the 7th International Symposium on Ballistics, 1983), p. 541

[34] R. Hamilton, D. MacKenzie, and H. J. Li, Engineering Computations 27, 967 (2010).

[35] Matweb, http://www.matweb.com/ Accessed on September 14, 2016.

[36] ANSYS, Mechanical APDL Technology Demonstration Guide 14.5, 435 (2012).

[37] O. T. Midling and Ø. Grong, Acta Metallurgica et Materialia 42, 1611 (1994).

[38] M. F. Ashby, J. Abulawi, and H. S. Kong, Tribology Transactions 34, 577 (1991).

[39] M. Awang, [Dissertation] West Virginia University, 57 (2007).

[40] R. B. McLellan and T. Ishikawa, J. Phys. Chem. Solids 48, 603 (1987).

[41] H. J. Zhang, H. J. Liu, and L. Yu, Transactions of Nonferrous Metals Society of China 23, 1114 (2013).

[42] X. K. Zhu and Y. J. Chao, Journal of Materials Processing Technology 146, 263 (2004). 